\title{
El respeto a los derechos adquiridos
}

SUMARIO: I. LAS CLAVES PARA EL ESTUDIO DE LOS DERECHOS ADQUIRIDOS. 1. La tensión entre la estabilidad del Derecho y su reforma. 2. Los derechos adquiridos como noción al servicio de la irretroactividad de las normas. El artículo 2.3 y las Disposiciones Transitorias del Código civil. 3. Los derechos adquiridos en la Constitución; en particular, el principio de seguridad jurídica. 4. La modulación de los derechos adquiridos según la naturaleza de la relación. En especial en el ámbito del Derecho Administrativo. II. SITUACIONES JURÍDICAS PREEXISTENTES Y CAMBIO NORMATIVO. 1. La heterogeneidad de situaciones jurídicas posibles. 2. Los derechos adquiridos. 3. Los efectos no consumados de los derechos. 4. Las expectativas.

\section{LAS CLAVES PARA EL ESTUDIO DE LOS DERECHOS ADQUIRIDOS}

\section{LA TENSIÓN ENTRE LA ESTABILIDAD DEL DERECHO Y SU REFORMA}

Pocos conceptos podrán encontrarse en el mundo del Derecho con mayor poder de atracción para el jurista que el de los derechos adquiridos. A poco que se profundiza en la categoría, la seducción inicial que despierta da paso, en cambio, a un cierto desencanto. Autores de diferentes tiempos y lugares han terminado confesando la dificultad de comprender o abarcar el concepto del que L. Duguit llegaría a proclamar que «nadie ha sabido nunca qué es» ${ }^{1}$. Todos creemos saber lo que son los derechos adquiridos con tal que no tengamos que definirlos. No se trata, sin embargo, de la clásica advertencia de JAVOLENO

\footnotetext{
${ }^{1}$ Cita tomada de A. Nieto, «Los derechos adquiridos de los funcionarios», RAP núm. 69, pág. 241.
} 
sobre el carácter peligroso de las definiciones jurídicas, sino de que los derechos adquiridos son, como ya afirmaba J.M. MANRESA, «uno de los problemas mas difíciles de la ciencia de la legislación» ${ }^{2}$ o, como mas tarde diría A. NiETO una «equívoca etiqueta» con la que, a veces, se pretende simplemente amparar «una serie de intereses creados, que no merecen o no debieran protegerse jurídicamente» ${ }^{3}$. De ahí la complejidad del concepto.

En un sentido elemental el sintagma derechos adquiridos no ofrecería especiales dificultades de comprensión. En cuanto al sustantivo está claro que nos estamos refiriendo al ámbito de los derechos subjetivos; y el adjetivo hace referencia, sin duda alguna, a que el derecho subjetivo ha nacido, ha sido patrimonializado por haberse cumplido los requisitos exigidos en la norma. Si hablamos del derecho de propiedad, por ejemplo, con la vista puesta en el artículo 609 del Código civil, habremos adquirido el derecho cuando haya operado el modo de adquisición que el propio precepto establece, es decir, cuando hayamos heredado o cuando hayamos celebrado un contrato de compraventa seguido de la tradición; mas raramente cuando hayamos podido ocupar una res nullius.

Ahora bien, esta constatación elemental, que a nadie ofrece dudas, no es la que ha hecho correr ríos de tinta, ni la que ha dado tantos quebraderos de cabeza a la doctrina, ni la que ha llevado al Tribunal Constitucional, en expresiones tan repetidas, a aludir a la dificultad ${ }^{4} \mathrm{o}$ al carácter huidizo ${ }^{5}$ de los derechos adquiridos. Lo que ocurre es que los derechos adquiridos constituyen una construcción teórica que incide de lleno en una de las cuestiones básicas del Derecho: en la de la tensión entre su estabilidad y su reforma, en la de la necesidad del mantenimiento de ciertas situaciones jurídicas frente a los cambios normativos posibles; expresa, en otros términos, la idea de garantía de las posiciones jurídicas individuales frente al poder conformador del Derecho, y esas son cuestiones de indudable trascendencia.

El Derecho y la regulación de las situaciones jurídicas no puede ser algo dado para siempre, petrificado e inamovible. La posibilidad de innovación y sustitución del ordenamiento jurídico es consustancial a la existencia misma del Derecho, en el que siempre existirá necesariamente una tensión entre estabilidad y reforma. Ya advertía J. FRANK que ni siquiera en las sociedades estáticas los hombres podían construir un sistema de reglas o normas omnicomprensivas, con

${ }^{2}$ Comentarios al Código civil español, T. I, 7ª ed., Reus, Madrid, 1987.

3 «Los derechos adquiridos de los funcionarios», RAP núm. 39, 1962, p. 241.

${ }^{4}$ Por ejemplo, en Sentencia 63/1982, de 20 de octubre.

${ }^{5}$ Calificativo que utilizó en su Sentencia 15/1981, de 7 de mayo, reiteradamente citada en ocasiones posteriores. 
respuesta a todas las cuestiones. Esto que no ha sido nunca posible, lo es menos aún en nuestro tiempo ${ }^{6}$. De ahí la necesidad continua de cambio, de adaptación y renovación del Derecho. En realidad, la ordenación del cambio normativo en su relación con las situaciones jurídicas preexistentes, esto es, la fijación de ese límite que concreta en una transformación normativa las situaciones jurídicas que han de considerarse intangibles frente a las que son disponibles para la nueva norma constituye, sin duda, una de las grandes cuestiones que debe resolver el Derecho, en cuanto resulta siempre difícil hallar un equilibrio entre posiciones cuyos puntos de apoyo se sitúan en la esencia misma del Estado constitucional; Estado al que como «social» $\mathrm{y}$ «democrático», le es inherente un amplio poder de conformación de la realidad social y económica ${ }^{7}$, en tanto que en su condición de «Derecho», se muestra garante de posiciones jurídicas individuales frente al Poder público. Tan peligrosa y rechazable ha de considerarse, en último término, la adscripción a posiciones favorables a un proceso de renovación normativa sin límites, como, en el ángulo opuesto, la defensa a ultranza de extensos ámbitos inmunes a la aplicación de un nuevo Derecho. Como ya señalara J.M MANRESA siguiendo a SiMONCELLI, en consideraciones efectuadas a propósito de la irretroactividad pero de plena validez aquí, la absoluta retroactividad de la ley «sería la muerte de la seguridad y de la confianza jurídica», en tanto que «la absoluta irretroctividad sería la muerte del desenvolvimiento del Derecho» ${ }^{8}$. Seguridad, confianza jurídica y libre desenvolvimiento del Derecho han de convivir en armonía porque así lo exige la propia Constitución; la cuestión radica justamente en hallar el cómo en cada uno de los supuestos que la realidad ofrezca. A las dificultades intrínsecas que la cuestión suscita en términos estrictamente jurídicos, ha de añadirse, por otra parte, su fácil politización. «En ningún campo

${ }^{6}$ Vid. L. ReCaSEns Siches: Panorama del pensamiento jurídico en el siglo XX, T. II, Porrúa, Méjico, 1963, p. 629.

${ }^{7}$ Es muy abundante la bibliografía que, desde perspectivas diversas, se ha adentrado en el análisis de los cambios del Derecho. En la obra de V. FERRARI: Acción jurídica y sistema normativo. Introducción a la Sociología del Derecho, Dykinson, Madrid, 2000, pp. 291 y ss., puede encontrarse una síntesis de las distintas corrientes filosóficas desde la que se ha explicado el fenómeno. Desde la perspectiva más concreta que aquí nos ocupa pueden consultarse las consideraciones efectuadas por L. DíEZ-PICAZO, Experiencias jurídicas y teoría del Derecho, $3^{\text {a }}$ ed., Ariel, Barcelona, 1973, pp. 295-312, F. LÓPEZ MENUDO «El principio de irretroactividad de las normas en la jurisprudencia constitucional». Estudios sobre la Constitución española. Homenaje al Profesor García de Enterría, T. I, Civitas, Madrid, 1991; en particular, pp. 467481, o L. Parejo Alfonso, Prólogo a la obra de F. CASTillo Blanco, La protección de confianza en el Derecho Administrativo, Marcial Pons, Madrid, 1998.

${ }^{8}$ Comentarios al Código civil español, T. I, op. cit., p. 159.

En la misma línea, pueden verse las mas recientes consideraciones de Y. GAUDEMET, en el Prólogo a la obra de C. YANNAKOPOulos, La notion de droits acquis en Droit Administratif français, LGDJ, Paris, 1997, p. XXI. 
como en éste, puede concluirse, en términos de F. LóPEZ MENUdo, son menos «inocentes» las construcciones doctrinales» 9 .

Éstas son, en definitiva, las coordenadas en las que se enmarcan las reflexiones siguientes y que se sitúan justamente en ese punto de fricción que toda nueva norma provoca en mayor o menor medida en su contacto con la realidad jurídica existente.

\section{LOS DERECHOS ADQUIRIDOS COMO NOCIÓN AL SERVICIO DE LA IRRETROACTIVIDAD DE LAS NORMAS. EL ARTÍCULO 2.3 Y LAS DisPosiciones TRANSITORIAS DEL CÓDIGO CIVIL}

Es en el ámbito de la incidencia del cambio normativo en su relación con las situaciones jurídicas preexistentes, en el que la categoría de los derechos adquiridos surge y se desarrolla. En efecto, esta doctrina hunde sus raices, aunque como ocurre habitualmente puedan encontrarse precedentes mas antiguos ${ }^{10}$, en la filosofía individualista y garantista prepoderante durante todo el siglo XIX ${ }^{11}$. La ley es retroactiva, señala G. RIPERT resumiendo una doctrina que no comparte, «cuando modifica los derechos adquiridos; no lo es cuando se limita a destruir simples expectativas ${ }^{12}$. De esta forma, y como ha destacado F. LÓPEZ MENUdo, la teoría de los iura quaesita llega a erigirse incluso en «elemento definidor de la misma idea de retroactividad»; «lesión a derechos adquiridos y retroactividad son ideas que viven en simbiosis y la mayor o menor extensión que se otorgue a una de las dos implica un encogimiento o estiramiento de la otra» ${ }^{13}$.

El Código civil prevé, por una parte, la posibilidad de retroactividad de las Leyes, si ellas mismas así lo disponen; pero, por otra, establece que las variaciones introducidas por el Código que perjudiquen derechos adquiridos no tendrán efectos retroactivos ${ }^{14}$. Ahora bien, el régimen que establece el Código civil plantea, pese a su aparente sencillez, dudas sustanciales que afectan a los dos conceptos que enlaza,

9 «El principio de irretroactividad de las normas en la jurisprudencia constitucional», op. cit., p. 457.

${ }^{10}$ Vid. las consideraciones efectuadas por F. DE CASTRO, Derecho civil de España, Civitas, Madrid, 1984, pp. 633-5.

${ }^{11}$ Vid., al respecto y entre otros, A. NIETO, «Evolución expansiva del concepto de expropiación forzosa», RAP, núm. 38, 1962; en particular, pp. 70-75, F. LóPEZ MENUdo, El principio de irretroactividad en las normas jurídico-administrativas, Instituto García Oviedo. Universidad de Sevilla, 1982, p. 97 o F. CAPILla RONCERO, Voz «Derechos adquiridos». Enciclopedia jurídica Civitas, Vol. II, Madrid, 1995, p. 2381.

${ }^{12}$ M. Planiol y G. RIPERT, Derecho civil, Editorial Pedagógica Iberoamericana, México, 1996, p. 31.

${ }^{13}$ El principio de irretroactividad de las normas jurídico-administrativas, op. cit., p. 129.

${ }^{14}$ Vid. artículo 2.3 e Introducción a las Disposiciones Transitorias. 
retroactividad y derechos adquiridos, cuya naturaleza está lejos de ser clara y pacíficamente admitida.

Los conceptos de retroactividad e irretroactividad son equívocos como lo demuestran las diferentes definiciones que de ellos se han da$\mathrm{do}^{15}$. De la regla general de la irretroactividad se ha dicho que es «un axioma de sentido común y de evidencia intuitiva» pero, a la vez, uno de las reglas más oscuras del Derecho ${ }^{16}$; de la retroactividad que es «un concepto jurídico indeterminado, por no decir el mas indeterminable de los conceptos jurídicos» ${ }^{17}$. De ahí advierte F. López MenUDO, en su excelente estudio sobre «La irretroactividad de las normas jurídico-administrativas», que sea necesario una especie de «termómetro de la retroacción» ${ }^{18}$. De hecho, puede considerarse ya clásica y plenamente asentada, además, en la jurisprudencia constitucional, la distinción entre retroactividades de grado máximo, medio y mínimo. La retroactividad auténtica o de grado máximo se produce, en expresión del Tribunal Constitucional, «cuando la disposición pretende anudar sus efectos a situaciones de hecho producidas con anterioridad a la propia Ley y ya consumadas»; la de grado medio, también llamada impropia, «cuando la Ley incide sobre situaciones jurídicas actuales aún no concluidas». La retroactividad, por último, de grado mínimo existe en los supuestos en los que la nueva legislación «alcanza a los efectos futuros de las situaciones generadas bajo la ley anterior ${ }^{19}$. Importa retener la distinción dada su trascendencia para el examen de las distintas situaciones jurídicas que pueden verse afectadas por la entrada en vigor de una nueva norma.

Si el concepto de retroactividad es equívoco, el de derecho adquirido no ofrece mayor claridad. La definición más clásica y permantemente citada de los iura quaesita se debe a GABBA que afirma ser derecho adquirido «todo derecho que entró a formar parte del patrimonio

${ }^{15}$ Así se corrobora en las diferentes definiciones de la doctrina. Baste citar las de G. RIPERT y M. Planiol y N. COVIELlo. Para los primeros, «la ley es retroactiva cuando vuelve sobre el pasado, ya sea para apreciar las condiciones de legalidad de un acto, o para modificar y suprimir los efectos ya realizados de un derecho. Fuera de esto no hay retroactividad, y la ley puede modificar los efectos futuros de los hechos o actos, aun anteriores a ella, sin ser retroactiva» (Derecho civil, op. cit., p. 32). N. CoviELlo, ofrece, por el contrario, una definición más estricta del concepto al estimar que «hay eficacia retroactiva no sólo cuando la nueva ley desconoce las consecuencias ya realizadas del hecho cumplido, es decir, cuando destruye las ventajas ya nacidas, sino también cuando, por una razon relativa a este hecho solamente, impide una consecuencia futura de un hecho ya cosumado» (Doctrina general del Derecho civil, traducción al castellano de la $4^{\mathrm{a}}$ edición italiana, Editorial Hispano-Américana, México, 1949 , p. 120).

${ }_{16}$ N. Coviello, Doctrina general del Derecho civil, op. cit., p. 109.

${ }^{17}$ El principio de irretroactividad de las normas jurídico-administrativas, op. cit., p. 494.

${ }^{18}$ El principio de irretroactividad de las normas jurídico-administrativas, op. cit., p. 502.

${ }^{19}$ SSTC, entre otras, 42/1986, de 10.IV, 126/1987, de 16.VII, 197/1992, de 19.XI, 173/1996, de 31.X y 182/1997, de 28.X. 
de alguno a consecuencia de un acto idóneo y susceptible de producirlo, en virtud de una ley del tiempo en que el hecho hubiere tenido lugar, aunque la ocasión de hacerlo valer no se presentase antes de la publicación de la ley nueva relativa al mismo» ${ }^{20}$. Esta definición a la que, desde luego, no le han faltado partidarios, no gozó nunca, sin embargo, de pacífica aceptación. Las numerosas críticas realizadas al concepto llegan, en ocasiones, incluso a afectar a su misma denominación -la locución, decía N. Coviello, «es defectuosa en sí misma», «substancialmente tautológica» en la medida en que no puede existir derecho sin su previa adquisición ${ }^{21}$-; y destacan, en otras, su indefinición en cuanto al momento en el que el derecho entra, efectivamente, a formar parte del patrimonio de la persona; la dificultad se acentúa si se tiene en cuenta, en términos de L. JossERAND, que la «mayor parte de los hechos, de los actos jurídicos, no comportan un desenlace inmediato» puesto que «sus efectos se prolongan durante un cierto tiempo ${ }^{22}$ y siempre, por otra parte, subsiste la dificultad de su distinción de las «simples expectativas», situaciones que sin haber llegado a la plena consolidación del derecho están reclamando algún genero de protección jurídica que no siempre el Derecho les otorga. Ante tantos y tan importantes inconvenientes ocurrirá, como bien explican, entre otros, N. Coviello o F. DE CASTRO, que los propios autores que formulan la doctrina de los derechos adquiridos se verán forzados, «a salvar ciertas situaciones de los efectos retroactivos, cubriéndolas con el título protector de los derechos adquiridos» o, en el ángulo opuesto, a excluir del concepto a otras «a las que se pretendían aplicar los efectos retroactivos de la nueva ley, para impedir su ilimitada permanencia» con lo que, en último término, «han estirado tanto, unas veces, y han recortado tanto, otras, el concepto de derecho subjetivo .. que en nada se parece ya al término utilizado normalmente por la ciencia jurídica» ${ }^{23}$. La teoría, llegará a concluir N. CoviELlo, «no sólo es vaga e incierta en sí misma, y sin sólida base científica, sino también de difícil aplicación, a menudo imposible, para resolver los casos variadísimos que se presentan ${ }^{24}$.

La insuficiencia de la teoría de los derechos adquiridos como fundamento de la irretroactividad de las normas dará origen a un importante movimiento doctrinal en el que convergen doctrinas muy diferentes a las que, sin embargo, unen el intento de ofrecer una explicación

\footnotetext{
${ }^{20}$ Esta definición, ofrecida en su obra Teoria della retroattività delle leggi, es citada por todos los autores que se han adentrado en el estudio de esta materia.

${ }^{21}$ Doctrina general del Derecho civil, op. cit., p. 113.

${ }^{22}$ Derecho civil I, Vol. I, Ediciones Jurídicas Europa-América, Buenos Aires, 1951, p. 76.

${ }^{23}$ Derecho civil de España, op. cit., p. 642.

${ }^{24}$ Doctrina general del Derecho civil, op. cit., pp. 112, 116 y 7.
} 
satisfactoria a los problemas de sucesión de normas en el tiempo sobre la base de la superación de la doctrina de los iura quaesita cuyo estudio fue prácticamente abandonado ${ }^{25}$. Ninguna de ellas, como, entre otros, nos explican L. DíEz-Picazo y A. Gullón, permite, sin embargo, «resolver con carácter general el problema de la transición. Toda solución dogmática y apriorística está llamada al fracaso» ${ }^{26}$. Ocurre además, como ha expuesto F. López MENUdo, que nuestro Tribunal Constitucional, ante la difícil tesitura de concretar la garantía consagrada en el artículo 9.3 de la CE -principio de irretroactividad de las disposiciones sancionadoras, no favorables o restrictivas de derechos individuales-, terminará por reconducir la irretroactividad «a un puro juego de efectos y límites formales, prescindiendo en cada caso de valorar la clase o el estado de la situación jurídica subyacente»; optará, en otros términos, por dotar a la garantía «de un sentido formalista capaz de hacerla funcionar con automaticidad e independencia de adherencias sustantivas» ${ }^{27}$ en detrimento así de las denominadas tesis sustancialistas de las que los iura quaesita constituyen, precisamente,

${ }^{25}$ Estas doctrinas han sido resumidas por diferentes autores. Vid. al respecto, y entre otras, las exposiciones de J. CASTÁN: Derecho civil español común y foral, T. I Vol. I, Reus, Madrid, 1982 pp. 615-620), D. BARBERo, Derecho privado, Ediciones Jurídicas Europa-America, Buenos Aires, 1967, pp. 132-5), D. EsPín CÁNOvas, Manual de Derecho civil español, Vol. I, Revista de Derecho Privado, Madrid, 1951, pp. 84-5, F. DE CASTRO, Derecho civil de España, op. cit., pp. 638-643, L. DíEz Picazo, y A. Gullón, Sistema de Derecho civil, Tecnos, Madrid, 2000, pp. 107-111 o F. LÓPEZ MENUDO, El principio de irretroactividad en las normas jurídicoadministrativas, op. cit., pp. 88-130.

No obstante, puede dejarse constancia de las más significativas. Destacan sin duda, entre ese amplio elenco de teorías, la de SAVIGNY, asentada en la distinción entre las normas relativas a la adquisición del derecho, que no pueden alcanzar a hechos acaecidos con anterioridad a su entrada en vigor, y las que se refieren a su existencia que, por el contrario, quedan al margen de esta limitación; la de L. Duguit (Traité de Droit Constitutionell, $3^{\mathrm{a}}$ ed. T. I, ed. Boccard, Paris, 1927, en particular, pp. 200 y ss.), desarrollada por G. JÈZE (Principios generales de Derecho I, traducción de la $3^{\mathrm{a}}$ edición francesa publicada en 1925, Depalma, Buenos Aires, 1948; en particular, pp. 115-267), cuyo centro de gravedad radica en la distinción entre situaciones jurídicas subjetivas, no modificables por una ley nueva, y situaciones jurídicas objetivas en las que sí puede incidir un nuevo Derecho sin ser por ello retroactivo; la teoría de los facta praeterita, asentada en la premisa de que todo hecho ha de quedar regulado por la Ley vigente del momento en el que se produce aunque no obstante, y como señalan N. COVIELLO (Doctrina general del Derecho civil, op. cit., pp. 117-120) o J. CASTÁN (Derecho civil español común y foral, op. cit., p. 618), no habrá acuerdo entre los defensores de esta teoría respecto a si la ley nueva afecta o no a las consecuencias ulteriores de esos hechos realizados bajo el imperio de la ley anterior; y, en fin, la que se considera la mas actual y depurada de todas ellas, la doctrina de P. RoubIER basada en la distinción entre el efecto inmediato de la ley y el efecto retroactivo, efecto prohibido y que se da cuando la norma afecta a hechos pasados y a efectos pasados de hechos pasados pero no cuando afecta a efectos futuros de hechos pasados [Le Droit Transitoire (Conflits des lois dans le temps), $2^{\mathrm{a}}$ ed. Dalloz et Sirey, Paris, 1960; en particular, pp. 293-439].

${ }^{26}$ Sistema de Derecho civil, Vol. I, op. cit., p. 110.

${ }^{27}$ El principio de irretroactividad de las normas en la jurisprudencia constitucional, op. cit., pp. 506-8. 
su expresión más destacada ${ }^{28}$. Tampoco puede olvidarse, por último, que, a diferencia del Código civil, la Constitución de 1978 no delimita la irretroactividad por referencia a los derechos adquiridos. El artículo 9.3 sólo garantiza la irretroactividad de «las disposiciones sancionadoras, no favorables o restricitvas de derechos individuales», derechos, éstos, que, aunque controvertidos en su interpretación, el Tribunal Constitucional terminará por identificar con los derechos fundamentales y libertades públicas, negando expresamente que coincidan con la «huidiza»y «difícil» categoría de los iura quaesita ${ }^{29}$.

Ahora bien, la insuficiencia de la teoría de los derechos adquiridos como elemento determinante de las situaciones jurídicas que ante una transformación normativa deben merecer la protección del Derecho, no supone la pérdida de valor de una institución en la que se expresan las garantías propias del principio de seguridad jurídica, en la actualidad reconocido en el artículo 9.3 de la Constitución, y que sigue desempeñando, como se verá, un papel determinante en el ámbito del Derecho intertemporal.

\section{LOS DERECHOS ADQUIRIDOS EN LA CONSTITUCIÓN; EN PARTICULAR, EL PRINCIPIO DE SEGURIDAD JURÍDICA}

Los derechos adquiridos han estado siempre engarzados, sin duda, a la idea de seguridad jurídica, principio que siempre ha estado presente en el ordenamiento jurídico con un carácter ambivalente. Si equiparamos seguridad con cumplimiento de la legalidad podemos llegar, en efecto, a la consagración de una justicia puramente formal o incluso a una seguridad enfrentada al concepto material de la justicia,

\footnotetext{
${ }^{28}$ En la obra de R. GAYA SICILIA, El principio de irretroactividad de las Leyes en la Jurisprudencia constitucional, Montecorvo, Madrid, 1987, puede encontrarse una sistematización y crítica de la jurisprudencia constitucional sobre la irretroactividad hasta dicha fecha.

${ }^{29}$ La determinación de los derechos incardinables en esos «derechos individuales» a los que se refiere el artículo 9.3 CE constituyó, como es sabido, uno de los problemas interpretativos más importantes del precepto; problema hoy resuelto por la propia jurisprudencia constitucional, pero que, en su día, sería objeto de posiciones doctrinales radicalmente enfrentadas. De una parte, la defendida por E. GARCÍA DE ENTERRÍA, para quien los «derechos individuales» del 9.3 CE coinciden con el conjunto de los derechos reconocidos en el Título I de la Constitución (Curso de Derecho Administrativo, I, $6^{a}$ ed., Madrid Civitas, 1993, pp. 8392); de otra, la sustentada por F. LóPEZ MENUDO, que, en términos más restrictivos, defendió la equiparación de esos derechos con los derechos fundamentales y libertades públicas, los reconocidos en los artículos 15-29 de la CE (El principio de irretroactividad de las normas jurídico/administrativas, op. cit., pp. 216-227). El Tribunal Constitucional se decantó por esta última tesis en una jurisprudencia resumida, más tarde, por el propio F. LÓPEZ MENUDO («El principio de irretroactividad de las normas en la jurisprudencia constitucional», op. cit., pp. 486-492). En la misma línea se pronunciarán posteriores Sentencias. Vid., por todas, la $104 / 2000$, de 13.IV.
} 
al solo servicio de la paz social ${ }^{30}$. Así, por ejemplo, habremos ganado un derecho tras una ocupación ilegal, por el solo transcurso del tiempo en determinadas condiciones o habremos perdido un derecho o una acción, también por el simple transcurso de otro periodo temporal. La institución de la cosa juzgada, con la santificación de la verdad formal inamovible, hunde, igualmente, sus raices en el mismo principio. El Código civil, como expresión del positivismo jurídico imperante en el siglo XIX, conoce, desde luego, este concepto de seguridad jurídica. En otras ocasiones, en cambio, la seguridad viene enlazada a concepciones sustancialistas, como en el caso del respeto a los derechos adquiridos que el Código proclama frente a la legalidad derivada de la Ley nueva, con lo que - como en el caso más señalado de la teoría del abuso del derecho o de la del fraude de ley-abre ventanas al mundo de los valores ${ }^{31}$.

Ahora bien, en la actualidad el principio de seguridad jurídica se ha constitucionalizado y su significado ha sido revalorizado. Incluso, como ha destacado A.E. PÉREz LuÑo, la seguridad ha sido llevada por el constituyente al Preámbulo mismo de la Constitución con «un sesgo tendencialmente axiológico»; lo que luego corrobora al establecerla como principio inmanente del ordenamiento jurídico ${ }^{32}$. Desde otro punto de vista, la seguridad se inserta incluso entre los derechos fundamentales -artículo 17.1- en una acepción ligada de manera inescindible a la libertad individual.

En lo que aquí importa, hemos de referirnos al principio consagrado en el artículo 9.3. No es fácil definir el principio de seguridad jurídica; principio importante donde los haya, y sobre el que existe una doctrina abundante y rica en contenidos y matices. La seguridad jurídica garantizada en el artículo 9.3 proyecta sus efectos en los mas diversos ámbitos, en el de la creación del Derecho, pero, también, en el de su aplicación e interpretación. Entre sus muchas manifestaciones, es garantía de correcta elaboración de la norma ${ }^{33}$, exigencia de certeza en el Derecho ${ }^{34}$ y de previsibilidad de su alteración. La seguri-

${ }^{30}$ Entre la abundante bibliografía que existe en esta materia, pueden consultarse, a título puramente ilustrativo, las obras de J.L. VILLAR PALASí, La interpretación y los apotegmas jurídico-lógicos, Tecnos, Madrid, 1975, p. 25 o N. BoBBIO, Contribución a la teoría del Derecho, Fernando Torres-Editor, Valencia, 1980, pp. 105 y ss.

${ }^{31}$ Los comentaristas del Código civil han hecho reiteradas alusiones a la fundamentación del respeto a los derechos adquiridos en el principio de seguridad jurídica. Vid. F. CLEMENTE DE DiEgo, Instituciones de Derecho civil, T. I, Artes Gráficas Julio San Martín, 1959, p. 160.

${ }^{32}$ La seguridad jurídica, Ariel, Barcelona, 1991, pp. 27-33.

${ }^{33}$ Vid., entre otras, STC 150/1990, 4.X.

${ }^{34}$ En la doctrina constitucional sobre el alcance de la seguridad jurídica garantizada por el artículo 9.3 CE destaca, en efecto, su consideración en términos de certeza del Derecho. La seguridad jurídica es, en frase muy repetida, «suma de legalidad y certeza en el Derecho» 
dad jurídica significa que podemos ajustar nuestra conducta a normas determinadas con consecuencias previsibles, que podemos confiar en que frente a la arbitrariedad posible se producirá una respuesta adecuada y que las situaciones jurídicas individuales no van a ser desconocidas o alteradas sin la adopción, en su caso, de las debidas garantías. De hecho, quienes se han adentrado en el estudio del alcance de la seguridad jurídica constitucionalmente garantizada no han dudado en incluir entre sus manifestaciones el debido respeto a los derechos adquiridos ${ }^{35}$, aunque la afirmación exige, desde luego, numerosas concreciones y matizaciones. El Tribunal Constitucional ha tenido, por otra parte, ocasión de desarrollar su doctrina sobre la seguridad jurídica del artículo 9.3. Así, se puede considerar ya plenamente consolidada la jurisprudencia constitucional que, en términos, por ejemplo, de la Sentencia 225/1998, de 25.XI, define la seguridad jurídica como «suma de certeza y legalidad, jerarquía y publicidad normativa, irretroactividad de lo no favorable e interdicción de la arbitrariedad, ... todo ello sin perjuicio del valor que, como principio constitucional, ostenta por sí misma»; esto es, la seguridad jurídica es «la suma de estos principios equilibrada de tal suerte que permita promover, en el orden jurídico, la justicia y la igualdad en libertad ${ }^{36}$, «lo que no quiere decir que no tenga valor por sí misma» ${ }^{37}$, pues, entonces, «no hubiera precisado de ser formulada expresamente» ${ }^{38}$. Conviene hacer hincapié en esta última idea; el valor autónomo que la seguridad jurídica tiene en el artículo 9.3 de la Constitución, la existencia de un contenido que le es inherente al margen del que pueda resultar de su conexión con el resto de los principios que se reconocen y ga-

(vid., entre otras, SS. 27/1981, de 20.VII,, 203/1998, de 15.X, 225/1998, de 25.XI, 49/1999, de 5.IV, con abundante cita, en las últimas, de pronunciamientos anteriores).

Son muchos los autores que han abundado en alguna o en todas estas características. Vid., entre otros, E. DíAz, Sociología y Filosofía del Derecho, Taurus, 1984, pp. 40-42, J.L. PALMA FERNÁNDEZ, La seguridad jurídica ante la abundancia de normas, Centro de Estudios Políticos y Constitucionales, Madrid, 1997, pp. 44-54 o L. LAVILLA Alsina Seguridad jurídica y función del Derecho, Real Academia de Legislación y Jurisprudencia, Madrid, 1999; en particular, pp. 47-49.

35 Así, y entre otros, L. LaVilla Alsina, Seguridad jurídica y función del Derecho, op. cit., p. 55, A.E. Pérez LuÑo, La seguridad jurídica, op. cit., pp. 96-98, F. CASTillo Blanco, La protección de confianza en el Derecho Administrativo, Marcial Pons, Madrid, 1998, pp. 89-97 y «El principio europeo de confianza legítima y su incorporación al Ordenamiento Jurídico español», Noticias de la Unión Europea, núm. 205, 2002, p. 36.

También, desde la perspectiva del Derecho comunitario, la doctrina ha considerado el respeto a los derechos adquiridos una manifestación del principio de seguridad jurídica. (Vid., por todos, T.C. HaRTLEY, The Foundations of European Community Law, Clarendon Press, 1994, p. 149).

${ }^{36}$ STC 27/1981, de 20.VII.

${ }^{37}$ STC 99/1987, de 11.VI. En el mismo sentido, STC 227/1988, de 29.XI.

${ }^{38}$ STC 27/1981, de 20.VII. 
rantizan en ese mismo artículo y apartado. Ahora bien, la claridad con la que la tesis se formula se pierde, sin embargo, cuando se intenta indagar, en esa misma jurisprudencia, en las exigencias concretas que para el proceso de formación y aplicación del ordenamiento jurídico derivan de la seguridad jurídica en sí misma considerada. De una parte, porque es inusual que el Tribunal Constitucional se pronuncie aisladamente sobre ella, pues lo normal, por el contrario, es que lo haga conjuntamente con alguno o algunos otros de los principios reconocidos en el artículo 9.3 de la Constitución, en particular, con el de la irretroactividad ${ }^{39}$; de otra, porque el examen de su doctrina deja la sensación de que a la seguridad jurídica garantizada en dicho precepto no se le han extraído todas sus posibles consecuencias; de que existen, aún, facetas por explorar, manifestaciones o expresiones del principio que el Tribunal, en ocasiones, apunta pero que, a la postre, no desarrolla. La jurisprudencia constitucional es clara en conectar la seguridad jurídica con la exigencia de certeza en el Derecho ${ }^{40}$, pero no existe, sin embargo, una jurisprudencia igualmente definida sobre el contenido del principio en la incidencia del proceso de creación del ordenamiento jurídico sobre las situaciones jurídicas preexistentes. A pesar de ello, y si se ahonda, no obstante, en esa jurisprudencia, se puede apreciar que el artículo 9.3 de la Constitución, en particular, los principios de seguridad jurídica y de irretroactividad sirven, en efecto, al Tribunal Constitucional para el establecimiento de un principio general de protección de dichas situaciones ante eventuales cambios normativos; idea también presente, por cierto, en la jurisprudencia del Tribunal Superior de Justicia de las Comunidades Europeas ${ }^{41}$.

39 A. SERRANO Triana se ha mostrado particularmente crítico con la jurisprudencia constitucional que, en su intento de delimitación de la seguridad jurídica, mezcla reglas y principios de naturaleza, a su juicio, «heterónoma». («La función de la seguridad jurídica en la doctrina del Tribunal Constitucional», Libro Homenaje al Profesor Jose Luis Villar Palasí, Ed. Civitas, Madrid, 1989; en particular, pp. 1257-1262).

${ }^{40}$ Es muy abundante, además, la jurisprudencia que abunda en el alcance de esa cualidad de certeza en el Derecho. Y así proclama que supone claridad en la norma a aplicar (Sentencias, entre otras, de 142/1993, de 28.V, 49/1999, 5.IV, 104/2000 o 13.IV, 235/2000, de 5.X); exigencia de que cuando una Ley, caso señalado de la de Presupuestos, cuente con un contenido constitucionalmente definido «no contenga mas disposiciones que las que correspondan a su función constitucional» (Sentencia de 203/1998, de 15.X en la que se recoge una consolidada doctrina vertida en otras muchas Sentencias anteriores); y necesidad de que toda innovación normativa se lleve a cabo de acuerdo con la regla establecida, se publique formalmente y contenga expresa derogación de las disposiciones a las que afecte (Sentencia 225/1998, de 25.XI).

${ }^{41}$ En las Conclusiones del Abogado general Sr. Geelhoed presentadas el 24.I.2001 en el Asunto C-62/00 se resumen las líneas generales de esa jurisprudencia. Así, y y tras señalar «que el principio de seguridad jurídica, forma parte del ordenamiento comunitario» declara que el mismo, entre otras manifestaciones «tiene por objeto garantizar que las situaciones y relaciones jurídicas reguladas por el Derecho comunitario son previsibles». Añade que «los justiciables no pueden confiar en que no se modifiquen las normas que les sean aplicables» si 
La Constitución, por otra parte, consagra otros principios que conjuntamente con la seguridad jurídica vienen igualmente a erigirse en freno de una acción normativa desconocedora de las situaciones jurídicas existentes; entre ellos, los de irretroactividad e interdicción de la arbitrariedad de los Poderes públicos ${ }^{42}$ reconocidos también en el artículo 9.3 de la Constitución, y que, al decir del Tribunal Constitucional, guardan «estrecho parentesco» con la propia seguridad ${ }^{43}, \mathrm{y}$ también el principio de responsabilidad de los Poderes públicos establecido en ese mismo artículo y apartado y la garantía indemnizatoria establecida en el artículo 33.3 de la Constitución para los supuestos de expropiación forzosa.

En el análisis singularizado de las diferentes situaciones posibles afectadas por un cambio normativo se examinará cómo se ha de armonizar, en cada caso concreto, las garantías propias de dichas situaciones - su inalterabilidad o, en su caso, las condiciones de su modificación o supresión - con la indudable capacidad innovadora de la norma, exigencias ambas derivadas de la propia Constitución.

\section{LA MODULACIÓN DE LOS DERECHOS ADQUIRIDOS SEGÚN LA NATURALEZA DE LA RELACIÓN. EN ESPECIAL EN EL ÁMBITO DEL DERECHO ADMINISTRATIVO}

Advertía J.L. ViLlar PALASí sobre la «gran cautela» y la «cierta prevención sistemática» con las que hay que acercarse «cuando se trata de aplicar técnicas generales del Derecho al campo del Derecho administrativo» ${ }^{44}$. La doctrina de los derechos adquiridos no sólo no constituye ninguna excepción a esta regla general, sino que, por el contrario, la confirma plenamente. La teoría de los iura quaesita, tal y como fue formulada en el contexto de la codificación, no puede, en

bien «pueden confiar en que los derechos nacidos de una normativa vigente no se reduzcan retroactivamente. El principio de irretroactividad ya quedó consagrado en la sentencia de 25 de enero de 1979, Racke (98/78)..... Sólo en casos muy singulares caben excepciones a esta línea general, como por ejemplo por necesidades económicas imperiosas relacionadas con la gestión de la organización común de los mercados agrarios o por un interés general imperativo.

${ }^{42}$ Sobre el alcance del principio de interdicción de la arbitrariedad en relación con los actos del Poder Legislativo me remito, entre otras, a las SSTC 27/1981, de 20.VII, 99/1987, de 11.VI y 227/1988, de 29.XI. En el ámbito más concreto que nos ocupa puede hacerse referencia a la STC 15071990, de 4.X en la que expresamente se declara que «la retroactividad posible de las normas tributarias no puede trascender la interdicción de la arbitrariedad».

${ }^{43}$ El propio Tribunal Constitucional se ha referido, en efecto, en numerosas ocasiones a la íntima conexión existente entre el conjunto de principios consagrados en el artículo 9.3 de la Constitución. Vid., por todas, Sentencia 99/1987, de 11.VI.

${ }^{44}$ Derecho Administrativo. Introducción y teoría de las normas, Universidad de Madrid, Madrid, 1968, p. 333. 
efecto, ser implantada en el ámbito del Derecho administrativo sin atender a sus propias singularidades y características ${ }^{45}$. Puede así hacerse referencia al carácter esencialmente cambiante de la norma administrativa frente a la estabilidad propia de la ley civil o la multiplicidad normativa característica del Derecho administrativo, el «Derecho desparramado en una infinidad de prescripciones particulares» en clásica expresión de A. MERKL ${ }^{46}$. Ahora bien, con ser importantes, no son éstas, sin embargo, las notas que verdaderamente singularizan el Derecho público frente al Derecho privado. En esta última rama del ordenamiento jurídico los sujetos se encuentran en una posición de igualdad ante el Derecho, que les reconoce, además, un amplio poder de disposición sobre su esfera jurídica; de ahí, justamente, la importancia del contrato, cuyas cláusulas se convierten en «ley» para las partes. En Derecho administrativo las cosas ocurren, sin embargo, de un modo muy diferente. Los sujetos privados se encuentran, en diferentes ámbitos de su actividad, en una relación de dependencia del Poder público que sirve de fundamento al establecimiento de regímenes objetivos caracterizados, entre otras notas, por sus amplias posibilidades de transformación y en cuyo seno la idea del ius quasitum se diluye extraordinariamente. Piensese, por ejemplo, en el régimen de los funcionarios públicos, en los diferentes estatutos de la propiedad privada o en la regulación de determinadas actividades económicas, vinculadas hoy, algunas de ellas, por las denominadas «obligaciones de servicio público universal». La doctrina del acto-condición, de gran arraigo hasta nuestros días ${ }^{47}$, de L. DUGUiT, desarrollada por G. JÈZE, alum-

\footnotetext{
${ }^{45}$ Muchos autores han llamado la atención, en unos u otros términos, sobre este hecho, ya sea desde la perspectiva del Derecho administrativo -así, F. FLEINER, Instituciones de Derecho Administrativo, Labor, Barcelona, 1933, p. 73 o, incluso, del Derecho civil, por ejemplo, L. JOSSERAND, Derecho civil I, vol I, op. cit., pp. 81-2.

${ }^{46}$ Teoría general del Derecho Administrativo, Editora Nacional, Méjico, 1980, p. 170.

Vid. también, al respecto, las consideraciones efectuadas por E. FosthofF, Tratado de Derecho Administrativo, Instituto de Estudios Políticos, Madrid, 1958, pp. 232-3.

${ }^{47}$ No es posible citar aquí a los muchos autores que total o parcialmente se adhieren a la teoría de L. DuguiT. y G. JÈZE, a título puramente ejemplificativo pueden citarse los siguientes. En Francia, R. Bonnard, Précis élémentaire de Droit Administratif, Sirey, Paris, 1996, P. WeIL, Le Droit Administratif, $11^{a}$ edición, PUF, Paris, 1964, pp. 10 a 19 o A. LAUBADÈRE, Traité de droit administratif, $8^{\text {a }}$ ed., 2 vols., LGDJ, Paris, 1980, Vol. I, pp. 15 a 21, en Italia F. FRANCHINI, Le autorizzazioni amministrative constitutive di rapporti giuridici tra l'amministrazione i privati, Giuffrè, Milano, 1957, pp. 67 y ss., en Alemania, E. ForsTHOFF, Tratado de Derecho Administrativo, op. cit., p. 221 y «Concepto y esencia del Estado social» en la recopilación de estudios de ForSTHOFF, ABENDROTH y DOEHRING: El Estado social, Centro de Estudios Constitucionales, Madrid, 1986, pp. 70 a 106. En España M. LóPEZ BENÍTEZ, Naturaleza y presupuestos constitucionales de las relaciones especiales de sujeción, Civitas, Madrid, 1994, pp. 235 y ss., J.M. ${ }^{a}$ Boquera Oliver, «Criterio conceptual del Derecho Administrativo», RAP, núm. 42, 1963, pp. 121 a 153, en especial pp. 124 y ss., o J.A. CARRILLO DONAIRE El Derecho de la seguridad y de la calidad industrial. Marcial Pons, Madrid, 2000, p. 589 y ss.
} 
brada precisamente como respuesta a la insuficiencia de la doctrina clásica de los derechos adquiridos para la resolución de los problemas de sucesión de normas que se plantean en Derecho administrativo, puede resumirse en los siguientes términos de G. JÈzE: «El acto de compraventa no es solamente un acto creador de situación jurídica individual, sino que es también un acto-condición: el acto de compraventa es la condición para que el comprador quede investido del status legal de propietario; para que la otra parte sea investida del privilegio de vendedor, que también es un statutus legal», de tal forma que el legislador «puede jurídicamente modificar estos status legales. Al hacerlo, no afecta a las situaciones jurídicas individuales creadas por la compraventa; modifica únicamente situaciones jurídicas generales creadas por la ley y simplemente motivadas por el acto de compraventa» ${ }^{48}$.

Desde otro punto de vista, pero de forma concordante, debe hacer alusión a la incidencia que en la teoría de los derechos adquiridos tienen las situaciones estatutarias. El propio SAVIGNY advertía de que las normas referentes a la existencia o no de una institución o bien a su modo de ser o a su duración, eran esencialmente retroactivas. Pues bien, las teorías de la institución aportan en cuanto a los derechos adquiridos perspectivas sugerentes. Ideada por M. HAURIOU y desarrollada básicamente por G. RENARD, la teoría es, en frase de E. BODENHEIMER, una «expresión del viraje, claramente visible en el mundo europeo, del individualismo a una forma de colectivismo». Si seguimos su exposición la teoría establece «un agudo contraste entre institución y contrato, pues mientras que en el contrato prevalece la idea de igualdad, la institución se fundamenta en la autoridad». «El principio de organización de la institución es el status y no el contrato»; «el bien común de la institución tiene que prevalecer sobre los intereses privados y subjetivos de sus miembros individuales»; «los derechos subjetivos son demasiados rígidos; el dinamismo y la adaptabilidad de la institución a nuevas condiciones sociales requiere que la situación de cada miembro se fije por un status objetivo» ${ }^{49}$.

Que esta concepción ha influido en el tratamiento de los derechos adquiridos está fuera de toda duda, como se demuestra, entre sus casos más significativos, en el ámbito del Derecho de los funcionarios públicos. Basta ver el distinto tratamiento jurisprudencial que dan a cuestiones similares la jurisprudencia social, a la vista de las relaciones jurídicas contractuales, y la jurisdicción contencioso-administrativa desde

\footnotetext{
${ }^{48}$ Principios generales de Derecho I, op. cit., pp. 189-190.

Vid., igualmente, L. DuguiT, Traité de Droit Constitutionell, op. cit., pp. 311-312.

${ }^{49}$ Teoría del Derecho, Fondo de Cultura Económica, Mexico, 1940, pp. 214-225.
} 
la óptica de las situaciones estatutarias de los funcionarios públicos ${ }^{50}$. Es evidente, por otra parte, que, en el Derecho administrativo en particular, no todas las situaciones posibles frente al poder conformador de la norma son reconducibles a la categoría de derechos subjetivos ${ }^{51}$, pues existen otras muchas ${ }^{52}$, comúnmente englobadas bajo la denominación de expectativas. Es más, aun dentro de cada categoría habrán de establecerse las oportunas diferenciaciones. Si nos situamos en el ámbito de los derechos subjetivos habrá, cuando menos, que diferenciar entre aquellos que ya han sido patrimonializados y han agotado sus efectos y los que, por el contrario, tienen aún pendientes algunos de sus efectos; si se piensa en las expectativas habrán igualmente de precisarse las diferentes situaciones que pueden esconderse bajo esa genérica denominación. Y todo ello sin perder nunca de vista el amplio poder de transformación propio del Derecho administrativo.

\section{SITUACIONES JURÍDICAS PREEXISTENTES Y CAMBIO NORMATIVO}

\section{LA HETEROGENEIDAD DE SITUACIONES JURÍDICAS POSIBLES}

Enlazando con las ideas que acaban de exponerse ha de reconocerse ante todo, y así resulta de la propia observación de la realidad, la

\footnotetext{
${ }^{50}$ Ya advertía A. NIETO, que tanto ha aportado al estudio de los derechos adquiridos en este ámbito, de que «es un error monstruoso considerar a los funcionarios en tensión frente al Estado-patrón, de la misma manera que los obreros y empresarios. La existencia de esta tensión es innegable ....; pero es producto de situaciones históricas. El papel del funcionario no es el de oponerse al Estado, sino el de formar parte del mismo». «Weimar no se ocupaba del funcionariado - como la Constitución de 1949- sino todavía de los funcionarios, cuidándose de garantizarles sus derechos adquiridos. La Constitución de Weimar miraba al pasado, y no al presente o al futuro» (El mito de la Administración prusiana, Instituto García Oviedo-Universidad de Sevilla, 1962, pp. 260-1).

${ }^{51}$ No es posible exponer aquí la teoría de los derechos públicos subjetivos. La bibliografía sobre la materia es abundante como corresponde a su importancia capital en el Derecho público. Sin afan exhaustivo y a título puramente ejemplificativo, me remito a las clásicas obras en la materia de G. JELLINEK: Sistema dei diritti pubblici subbietivi, traducción italiana de la $3^{\text {a }}$ edición alemana, Società Editrice Libraria, Milán, 1912, SAVIGNY.. En nuestra doctrina, me remito a las igualmente clásicas reflexiones de F. GARRIDO FALLA, «Las tres crisis del derecho subjetivo». Estudios dedicados al Profesor García Oviedo, Vol. I, Universidad de Sevilla, 1954, pp. 177-217 o E. GARCía DE ENTERRía: «Sobre los derechos públicos subjetivos», REDA núm. 6, 1975, pp. 429 y ss.

En la obra de J.A. SANTAMaría PASTOR, Fundamentos de Derecho Administrativo I, Centro de Estudios Ramón Areces, Madrid, 1988, pp. 891-5, puede encontrarse una exposición del concepto con cita de las referencias bibliográficas.

${ }^{52}$ Ha sido, probablemente, la doctrina italiana la que más intensamente se ha dedicado al análisis de las diferentes situacions subjetivas que puedan generarse en aplicación del Derecho Administrativo. Vid., por todos, R. AlESSI, Instituciones de Derecho Administrativo, T. II, traducción de la $3^{\text {a }}$ edición italiana, Bosch, Barcelona, 1970, pp. 444 y 5 y «La crisi attuale della nozione di Diritto soggettivo ed i suoi possibili riflesi nel campo del Diritto pubblico» Scritti Giuridici in memoria di V.E. Orlando, Padova-Cedam, 1957, pp. 18-20.
} 
extrema variedad de situaciones jurídicas individuales posibles que eventualmente pueden verse afectadas por un cambio normativo, lo que indudablemente aboga por un análisis singularizado. Siendo ello así, es frecuente la apelación, tanto en la doctrina como en la jurisprudencia, a dos grandes tipos de situaciones jurídicas individuales posiblemente afectadas por un cambio normativo: los derechos, comúnmente adjetivados como perfectos o adquiridos, y las expectativas, a las que suelen acompañarse de expresiones tales como «meras» o «simples» en un intento, sin duda, de destacar su mayor vulnerabilidad, su escasa resistencia ante la fuerza innovadora de la disposición que se promulga; de ahí la importancia de examinar unos y otras.

\section{LOS DERECHOS ADQUIRIDOS}

Es indiscutible que en el extremo superior de esa «escala» de posiciones jurídicas se sitúan los derechos adquiridos. Aunque se trata, como ya se señaló, de una categoría controvertida, goza, sin embargo, de plena actualidad como se constata en la cláusula «sin perjuicio de los derechos adquiridos» presente en muchas de nuestras normas ${ }^{53}$ y como se desprende, también, de su constante invocación por los Tribunales y de la resistencia de la doctrina al abandono de su estudio. Ahora bien, ¿cuál es la situación jurídica que se protege con esta categoría?

Recogiendo las muchas expresiones doctrinales y jurisprudenciales al uso, el derecho adquirido puede identificarse con el derecho re-

${ }^{53}$ Son muy numerosas, en efecto, las disposiciones de nuestro ordenamiento jurídico que consagran de manera expresa el respeto a los derechos adquiridos. La mayoría de los Estatutos de Autonomía, por ejemplo, declaran el respeto a los derechos adquiridos de cualquier orden y naturaleza que tengan los funcionarios transferidos a la Comunidad Autónoma. Así lo hacen los Estatutos del País Vasco (D.T. $2^{\mathrm{a}}$ ), La Rioja (D.T. $9^{\mathrm{a}}$ ), Murcia (D.T. $4^{\mathrm{a}}$ ), Madrid (D.T. $3^{\text {a }}$ ) o Asturias. Sobre el alcance y significado de esas cláusulas, puede verse la STC 100/1990, de 30.V. La protección de derechos adquiridos de los funcionarios y otro personal figura en otras muchas disposiciones (entre otras muchas, D.T. $1^{\text {a }}$ de la Ley 4/1980, de 10.I, del Estatuto de la Radio Televisión española, D.T.2 $2^{\text {a }}$ de la Ley 13/1982, de 17.XII, de Colegios Profesionales de Cataluña, D.A. $2^{\text {a }}$ de la Ley 42/1997, de 14.XI, ordenadora de la Inspección de Trabajo, D.A. $2^{a}$ de la Ley 6/1998, de 28.V, de Régimen jurídico de las Cámaras agrarias de la Comunidad de Madrid). También es frecuente que lo hagan en el ámbito de la Legislación tributaria (vid., entre otras, D.T. $1^{\text {a }}$ de la Ley 61/1978, de 27.XII del Impuesto de Sociedades, D.T. $2^{\text {a }}$ de la Ley 29/1987, de 18.XII, del Impuesto sobre Sucesiones y Donaciones) y en otras muchas materias como puedan ser el régimen de los seguros (D.T.7.2 de la Ley 30/1995, de 8.XI, de Ordenación y supervisión de Seguros privados), los partidos y asociaciones políticas (D.T. única de la Ley 54/1978, de 4.XII), o las aguas (D.T. $2^{\mathrm{a}}$ ), el respeto a los derechos adquiridos también aparece en otras disposiciones. Por ejemplo, D. 2414/1961, de 30.XI, del reglamento de actividades molestas, nocivas, insalubres y peligrosas (D.F. $7^{\mathrm{a}}$ ), la Ley 8/1972, de 10.V, de construcción, conservación y explotación de autopistas en régimen de concesión (artículos 10 y 40), la Ley 22/1973, de 21.VII, de minas y RD 2875/1978, de 25.VIII, por el que se dicta el Reglamento general para su desarrollo (arts. 12 y 59 ). 
conocido, el derecho subjetivo perfecto ${ }^{54}$, «el patrimonializado por un sujeto» ${ }^{55}$, el incorporado a su patrimonio ${ }^{56}$. Los derechos adquiridos son, en otros términos que reflejan esa misma realidad, aquellos derechos de los que, según dice la STS de 24.III.199757, se han «dado todos los elementos de los que, conforme a dicha norma, depende su nacimiento»; lo que es lo mismo, los derechos consolidados para los que se requiere, como expresa la STS de 24.X.2000 ${ }^{58}$, «la concurrencia de cuantos requisitos sean necesarios para el perfeccionamiento del acto, según las exigencias de la anterior normativa ${ }^{59}$, definiciones, por otra parte, en las que también viene a coincidir la doctrina ${ }^{60}$.

A pesar de que el Tribunal Constitucional ha rehusado expresamente «cualquier intento de aprehender la huidiza teoría de los derechos adquiridos» ${ }^{61}$, de la que dice que «no está acogida deliberadamente en la Constitución» ${ }^{62}$, de su doctrina, formulada con ocasión de la interpretación del alcance del principio de irretroactividad consagrado en el artículo 9.3 de la Constitución, se deduce, en cambio, con claridad el reconocimiento en favor de los particulares de auténticos derechos subjetivos intangibles frente al legislador posterior, de derechos perfectos, en referencia, y el Tribunal Constitucional hace

\footnotetext{
${ }^{54}$ Interesa notar cómo la doctrina utiliza indistintamente las expresiones de «derechos subjetivos» y «derechos adquiridos» como términos sinónimos. Así, F. DE CASTRO, Derecho civil de España, op. cit., pp. 638-643 o F. LóPEZ MENUDO, El principio de irretroactividad de las normas en la jurisprudencia constitucional, op. cit., pp. 495-7.

${ }^{55}$ P. Escribano Collado, Voz «Expectativa». Enciclopedia Jurídica Civitas, Vol. II, op. cit., p. 2997.

${ }^{56}$ SSTS de 10.VI.1980 (RJ 3170), 9.XI.1998 (RJ 8796) y 31.X.1997 (RJ 7241).

${ }^{57}$ RJ 2499. En la misma línea, Sentencia de 25.X.1982 (RJ 6438).

${ }^{58} \mathrm{RJ} 10369$.

${ }^{59}$ En el mismo sentido, SSTS de 27.II.1980 (RJ 3030), 19.X.1981 (RJ 4485), 21.VI.1982 (RJ 4821), 28.IX.1984 (RJ 5390), 4.IV.1986 (RJ 4614), 21.XII.1990 (RJ 10177), 4.VII.1997 (RJ 6322) o 16.III.1999 (RJ 2901).

${ }^{60}$ Aunque es inusual, desde luego, encontrar en la doctrina de nuestros días definiciones del derecho adquirido, cuando aparecen, lo son en términos parecidos a los de la jurisprudencia citada. Vid., por ejemplo, las ofrecidas por A.E. PÉREZ LUÑo, La seguridad jurídica, op. cit., p. 96, o A. CARRETERO PÉREZ, «Los derechos adquiridos y la edad de jubilación de jueces y magistrados», Actualidad Administrativa, núm 40, 1986, p. 761.

Fuera de nuestras fronteras pueden citarse, entre las definiciones más recientes, la ofrecida en la doctrina francesa por C. YANNAKOPOULOS, que en su aún reciente monografía sobre los derechos adquiridos los define como «los efectos intangibles de los actos creadores de derechos, no los actos mismos. No es el derecho al mantenimiento del acto o norma creadora de derechos, sino el derecho al mantenimiento de una situación jurídica concretizada y adquiririda» (La notion de droits acquis en Droit Administratif français, L.G.D.J., Paris, 1997, pp. 541 y 2). En la doctrina italiana, G. GOTTANELLI DE' SANTI señala que los autores actuales no se separan sustancialmente de la clásica definición de GABBA, si bien puntualiza que la «la expresión se refiere, también a fenómenos que en sentido estricto no son derechos subjetivos y que parece mas oportuno hablar de situaciones jurídicas mas que de derechos» voz «Diritti quesiti», Enciclopedia Jurídica, p. 1.

${ }^{61}$ STC 27/1981, de 20.VII.

${ }^{62}$ SSTC 27/1981, de 20.VII y 108/1986, de 29.VII.
} 
aquí acopio de expresiones ya clásicas en la jurisprudencia del Tribunal Supremo, a «situaciones agotadas» ${ }^{63}$, «consumadas» ${ }^{64}$, al «derecho incorporado al patrimonio de su titular ${ }^{65}$, al «consolidado» ${ }^{66}$, a los «integrados en el patrimonio del sujeto» ${ }^{67}$, a aquellos, en suma, cuyos efectos puedan considerarse "agotados, definitivos o conclusos» ${ }^{68}$. Aunque el Tribunal Constitucional niegue, pues, que la categoría de los derechos adquiridos haya sido constitucionalizada, su jurisprudencia reconoce así la existencia de situaciones jurídicas claramente incardinables en dicho concepto. Esta afirmación que, en apariencia, pudiera parecer un tanto contradictoria, no lo es, sin embargo, si se tiene en cuenta que la oposición del Tribunal a la existencia constitucional de derechos adquiridos constituye una tesis formulada en el ámbito exclusivo de la interpretación del principio de «irretroactividad de las disposiciones sancionadoras, no favorables o restrictivas de derechos individuales» reconocido en el artículo 9.3; esto es, lo que el Tribunal Constitucional ha establecido es que no pueden esgrimirse derechos adquiridos como argumento en defensa de la irretroactividad de las normas, mas allá de las materias definidas en este precepto; entre ellas, los «derechos individuales», categoría que, como se dijo, ha encontrado concreción en los derechos fundamentales y libertades públicas, no pudiendo en modo alguno equiparse a la de los iura quaesita. En otros términos, a lo que el Tribunal Constitucional se opone no es a que existan derechos adquiridos, sino a que la retroactividad de la norma esté proscrita siempre que estén presentes derechos de esta naturaleza, porque ello supondría en verdad una petrificación del ordenamiento jurídico contraria a los propios valores constitucionales $^{69}$. El Tribunal Constitucional defiende, en suma, la posibilidad de que, fuera de los ámbitos expresamente delimitados en aquel precepto, las normas jurídicas puedan tener efectos retroactivos, existan o no derechos adquiridos al amparo de la normativa anterior $^{70}$.

Ahora bien, una cosa es que el constituyente no proscriba la retroactividad con carácter general, fuera de las mencionadas materias establecidas en el artículo 9.3 -disposiciones sancionadoras, no favora-

\footnotetext{
${ }^{63}$ SSTC 108/1986, de 29.VII, 227/1988, de 29.IX.

${ }^{64}$ STC 197/1992, de 19.IX.

${ }^{65}$ STC 6/1983, de 4.II.

${ }^{66}$ STC $127 / 1987$, de 16.VII.

${ }^{67}$ SSTC 99/1987, de 11.VI y 70/1988, de 19.IV.

${ }^{68}$ STC 386/1993, de 23.XII.

${ }^{69} \mathrm{Vid}$., entre otras muchas y a título puramente ejemplificativo, las SSTC 27/1981, de 20.VII, 6/1983, de 4. II, 99/1987, de 11, 227/1988, de 29.XI o 178/1989, de 2.XI.

${ }^{70}$ Así se reconoce expresamente en las Sentencias, entre otras, 27/1981, de 20.VII, 42/1986, de 10.IV y 197/1992.
} 
bles o retrictivas de derechos individuales-, y otra distinta sería interpretar, a contrario sensu, que la consagra, lo que indudablemente no es cierto. El constituyente es consciente de que la regla general del ordenamiento jurídico, sancionada, desde antiguo, en el artículo 2.3 del Código Civil, es la de la irretroactividad de las normas; de ahí que, de una parte, hayan de considerarse excepcionales los supuestos de retroacción de la norma y, de otra, que deban preverse mecanismos de protección para las ocasiones en las que, efectivamente, la nueva norma afecta a derechos adquiridos.

La retroactividad de la norma y, por consiguiente, la alteración de las situaciones consolidadas ha de estimarse, en efecto, excepcional porque así lo impone el principio de seguridad jurídica del que el respeto a los derechos adquiridos, según considera la doctrina, como quedó dicho, es una de sus muchas manifestaciones. El Tribunal Constitucional, por otra parte, como ya tuvimos ocasión de exponer antes con detalle, ha desarrollado una amplia doctrina sobre el concepto de seguridad. En ella alude al mantenimiento de «las situaciones de hecho producidas con anterioridad a la Ley y ya consumadas», por lo que sólo «exigencias cualificadas de interés general podrían imponer el sacrificio del principio» ${ }^{71}$; exigencias cuya valoración corresponde interpretar, lógicamente, al Poder público autor de la norma y cuyo enjuiciamiento, llegado el caso, ha de hacerse, según destaca esa misma jurisprudencia constitucional, desde la consideración conjunta de los principios de irretroactividad y seguridad jurídica y «los que con él se relacionan, esto es, el valor de la justicia en su vertiente de interdicción de una regulación arbitraria y discriminatoria (art. 1 CE), y la expropiación de derechos, que se afirman adquiridos o consolidados, sin la correspondiente indemnización (arts. 33.3 y $106.2 \mathrm{CE}) »^{72}$.

En las ocasiones, excepcionales desde luego, en las que la norma retroactiva produzca una privación de derechos adquiridos habrán de ponerse en marcha los cauces indemnizatorios establecidos en la propia Constitución tal y como reconocen tanto el Tribunal Constitucional como el Supremo ${ }^{73}$, así como el Tribunal Europeo de Derechos

${ }^{71}$ SSTC, entre otras, 42/1986, de 10.IV, 197/1992, de 23.XII o 182/1997, de 28.XI.

${ }^{72}$ Vid., SSTC 99/1987, de 26.VI, 225/1998, de 25.XI y 273/2000, de 15.XI.

El Tribunal Supremo ha insistido en esta misma idea en Sentencias, por ejemplo, de 14.XII.1999 (RJ 9792) y 15.VI.2000 (RJ 6742).

${ }^{73}$ Por todas, puede verse su Sentencia de 16.V.2000 (RJ 5487) en la que, con cita de otras muchas tanto del Tribunal Constitucional como del propio Tribunal Supremo, se afirma la evidente conexión existente «entre el perjuicio causado por una disposición de carácter general -en este caso con valor de ley-inherente a la privación singular de un derecho o interés económico consolidado o incorporado al patrimonio del afectado y el mecanismo indemnizatorio a que da lugar la aplicación del principio de responsabilidad patrimonial de los poderes públicos ... que procede otorgar a quienes, por causa de interés general, resulten perjudicados en sus bienes y derechos». 
Humanos $^{74}$. A la excelente obra de R. GALÁN VIOQUE sobre La responsabilidad del Estado legislador ${ }^{75}$, y a la extensa bibliografía y jurisprudencia que en ella se cita, me remito para un análisis del valor de la responsabilidad de los Poderes públicos y la expropiación forzosa como títulos fundamentadores de la indemnización de los daños causados a particulares por la actuación normativa del Estado; títulos cuya importancia ha sido ponderada por numerosos autores en el tratamiento específico de esta cuestión ${ }^{76}$.

En definitiva, en el artículo 9.3 de la Constitución, y al margen de su concreta regulación de la irretroactividad, encuentra cabal fundamento la protección de los derechos adquiridos. Las situaciones jurídicas consumadas, agotadas al amparo del Derecho que se deroga, están, en principio y con carácter general, a salvo del poder de innovación de la nueva norma, obligada, en consecuencia, a su respeto por imperativo no sólo del principio de seguridad jurídica, sino, también, de otros que con ella se relacionan; en particular, los de irretroactividad de determinadas normas, interdicción de la arbitrariedad y responsabilidad de los Poderes públicos. De la suma de todos ellos resulta una regla general de respeto a los derechos incorporados al patrimonio de sus titulares en aplicación del ordenamiento que se sustituye, derechos por cuya privación habrán de ser indemnizados si la satisfacción del interés público obliga excepcionalmente a ella, como ha ocurrido, entre los casos mas señalados en la historia reciente, con la declaración de demanialidad de determinadas propiedades privadas efectuada por la Ley 22/1988, de 28 de julio, de Costas ${ }^{77}$. Ya hemos dicho, además, que son muchas las disposiciones de nuestro ordenamiento jurídico que, en las mas diversas materias, declaran expresamente su respeto a los derechos adquiridos ${ }^{78}$, a las que han de añadirse aquéllas otras en las que el Derecho, obligado a sacrificarlos en aras de los superiores intereses de la comunidad, fija las correspondientes medidas compensatorias en lo que constituye la muestra mas palmaria de que, efectivamente, el respeto a estas situaciones jurídicas se encuentra en la base de nuestro ordenamiento jurídico ${ }^{79}$.

\footnotetext{
${ }^{74}$ Vid., por todas, su Sentencia de 23.XI.2000.

${ }^{75}$ Cedecs, Barcelona, 2001.

${ }^{76}$ Vid. al respecto, y entre otras, las consideraciones de L. LaVILLa Alsina, Seguridad jurídica y función del Derecho, op. cit., p. 56 o F. GARRIDO FALLA, Tratado de Derecho Administrativo, Vol. I, Centro de Estudios Constitucionales, Madrid, p. 215.

${ }^{77}$ Vid. Disposiciones Transitorias de la Ley 22/1988, de 28.VII y STC 149/1991, de 4,VII. Vid. sobre la materia C. Horgue BaEna El deslinde de costas, Tecnos, Madrid, 1995; en particular, pp. 267-284.

${ }^{78}$ Vid. disposiciones citadas en nota 43.

${ }^{79}$ Existen ocasiones, en efecto, en las que el Derecho establece medidas compensatorias por lo que el mismo considera una privación de derechos adquiridos. Además del ya citado
} 
Los innegables problemas que el Derecho intertemporal plantea no se suscitan sin embargo, por lo general, en este ámbito de los derechos patrimonializados con efectos jurídicos consumados o agotados; se originan en relación con situaciones de diferente naturaleza de las que nos ocupamos a continuación bajo las rúbricas respectivas de «los efectos no consumados de los derechos» $\mathrm{y}$ «las expectativas».

\section{LOS EFECTOS NO CONSUMADOS DE LOS DERECHOS}

En el intento de sistematizar las distintas situaciones jurídicas con las que puede encontrarse una norma nueva, hemos de hacer referencia ahora a los supuestos en los que, habiéndose cumplido con los presupuestos de hecho determinantes del nacimiento de un derecho, sus efectos están pendientes, no se ha disfrutado de ellos, no se han incorporado aún, al menos en toda su extensión, al patrimonio de su titular. Son los supuestos que habitualmente se producen en las situaciones de consecuencias jurídicas de tracto sucesivo anudadas a un hecho anterior. En estos casos, ¿ puede afirmarse que el particular dispone de derechos adquiridos frente al Poder normativo?; en otros términos, ¿tiene derecho a la intangibilidad de estos efectos futuros o son éstos, por el contrario, disponibles para la nueva norma? La cuestión expuesta puede ejemplificarse en uno de sus supuestos más significativo: el de las exenciones tributarias y otros beneficios fiscales cuando la realización de determinados hechos por el contribuyente proyecta sus consecuencias en sucesivos periodos impositivos. En estos casos, ¿tiene el beneficiario derecho a que se agoten todos los efectos del hecho que lo generó aun cuando en el transcurso del tiempo necesario para su realización se reforme la norma?

La jurisprudencia en esta materia es extremadamente confusa, pero se puede encontrar en ella un número significativo de sentencias que, con argumentos distintos y no siempre del todo coincidentes, reconocen el derecho de los particulares a la consumación o ago-

caso de la Ley de Costas, puede aludirse al ofrecido por el RDLeg. 1/2001, de 20.VII, de Aguas (vid., en particular, D.T. $2^{\mathrm{a}}$ ) o al Derecho urbanístico que, igualmente, parte de un principio de respeto a los derechos adquiridos, aunque, como reiteradamente ha establecido el Tribunal Supremo, las modificaciones de los planes urbanísticos «no puede encontrarse limitada por los derechos adquiridos al amparo del planeamiento anterior» cuando «las circunstancias concurrentes así lo demanden en aras de la mejor satisfacción de los intereses generales» (Sentencia de 27.IV.1999, RJ 3093), sin perjuicio, dice la Sentencia de 13.VI.1984 (RJ 3609), de las consecuencias indemnizatorias o compensatorias que el sacrificio de esos derechos adquiridos produzcan en el momento de la ejecución del nuevo planeamiento». Otras muchas Sentencias pueden consultarse en esta misma línea. Entre otras, las Sentencias de 8.V.1989 (RJ 1989), 4.VII.1997 (RJ 5720), 29.IX.1998 (RJ 6953), 10.II.1999 (RJ 677), 28.I.2000 (RJ 578). 
tamiento de los efectos jurídicos inherentes a hechos producidos bajo la vigencia de una disposición que se altera. Son los casos, entre los más ilustrativos, de la Sentencia del Tribunal Supremo de 20.XII. $1990^{80}$, en la que se reconoce a la empresa recurrente el derecho adquirido al régimen de transparencia fiscal por el que había optado en aplicación de las Leyes del Impuesto sobre la Renta de 1978 y que estaba aún en vigor cuando en el año 1985 una nueva norma reguladora del impuesto procede a su supresión ${ }^{81}$, de 17.IX.1998 ${ }^{82}$, en la que se considera que determinadas exenciones ligadas a la construcción de viviendas de protección oficial nacieron con la formalización de la escritura de compraventa de la parcela, por lo que se tiene derecho a su disfrute aun cuando posteriormente se hubieran modificado ${ }^{83}$, o

${ }^{80}$ RJ 586/1997.

${ }^{81}$ Quizá interese, para ilustrar bien la idea, reproducir algunos párrafos de la Sentencia: «La cuestión planteada en este recurso de apelación es si la entrada en vigor de esta Ley 48/1985, el 1 de enero de 1986, implica o no que la recurrente .... pierda el derecho al régimen de transparencia voluntaria, por el ejercicio 1986, que le restaba del trienio 1984 a 1986, por el que había optado. No existe ninguna Disposición Transitoria que contemple y regule esta clara situación intertemporal .... Es claro que «Asturiana de Vinos, SA» adquirió por virtud del ejercicio de la opción prevista en el artículo 12.3 de la Ley 4471978, de 8 de setiembre ... y el artículo 19.2 de la Ley 6171978, de 27.XII ... dentro del llamado régimen de transparencia fiscal voluntaria, el derecho a disfrutar durante los ejercicios 1984, 1985 y 1986 de la exención total del Impuesto sobre Sociedades a cambio, por supuesto, de la correspondiente imputación de renta a los socios o accionistas ..... Por ello, la «base del negocio», entendiendo por tal el soporte fáctico previsible de la opción o decisión voluntaria por el régimen de transparencia fiscal, eran todos los factores económico-fiscales del trienio 1984-1986 ... Es innegable, por tanto, que la supresión del régimen de transparencia fiscal voluntaria para el ejercicio 1986 ... implica una aplicación retroactiva de la misma, en la medida en que vulnera derechos adquiridos al régimen fiscal referido ..... ha de concluirse que «Asturiana de Vinos, SA» tiene derecho a continuar durante el ejercicio 1986, con el régimen de transparencia fiscal voluntaria, hasta agotar, por tanto, el trienio 1984/1986, por el que se concedió, dentro de dicho régimen, la exención total por el impuesto sobre Sociedades, sin que pueda al término del mismo, ejercitar la prórroga prevista en las normas derogadas, porque ésta, no es un derecho adquirido, sino una expectativa, pendiente de que subsistan, cuando se cumpla el plazo, las normas que la permitían ...».

${ }^{82}$ RJ 7518.

${ }^{83}$ Señala la Sentencia que aunque no ha de entrarse en la «polémica sobre la existencia o no de un derecho adquirido «versus» una simple expectativa a tal exención, sin embargo si coadyuva en la ratificación de su reconocimiento, que no sólo se apoya en la norma vigente, debidamente interpretada, sino también en un derecho adquirido a la misma exención el 7 de setiembre de 1976, cuando se formalizó la escritura de compraventa de la parcela, pues, en el caso de autos, la exención nació como un compromiso de la Administración Pública resultado de una actuación «concertada», y no sólo como efecto de una norma jurídica de derecho objetivo».

La Sentencia de 9.XI.1998 (RJ 8796) en la que, de nuevo, se enjuicia el posible derecho al mantenimiento de ciertas exenciones declara que «la doctrina de los derechos adquiridos exige la incoporación al patrimonio de su titular del efectivo derecho supuestamente desconocido y esta incorporación no se produce por la simple declaración normativa, sino que se requiere la existencia de un positivo acto de reconocimiento del derecho que, en este caso, no puede ser modificado por norma posterior». 
de la de 15.X.1998 $8^{84}$, en la que se reconoce igualmente el derecho al mantenimiento de la medida de fomento que se venía disfrutando, más tarde suprimida por la norma, «porque el beneficio de que se trata fue concedido como tal medida de fomento y significó la asunción por la entidad apelante, conforme se desprende del contenido de la Orden de 1974, de un correlativo esfuerzo para realizar la actividad que la Administración quería incentivar. Prácticamente, pues, equivale a un concierto solemne con el Estado .... ${ }^{85}$. Expresivas de esta misma idea son, también, las Sentencias de 5.III.1993 ${ }^{86}$ y 27.VI.199487, que reconocen a determinadas empresas pesqueras constituidas por armadores nacionales con socios extranjeros «derechos adquiridos» al mantenimiento de la exención de pago de derechos arancelarios y compensatorios establecidos por el Gobierno y suprimidos, más tarde, como consecuencia de la adhesión de España a las Comunidades Europeas ${ }^{88}$ o la de 30.VI.1995 ${ }^{89}$, que declara el derecho de una naviera al abono de la «prima de producción específica» que la Administración le negaba, porque ésta «se adquiere desde el momento en el que el beneficiario cumple con todos los requi-

\footnotetext{
${ }^{84}$ RJ 7913.

${ }^{85}$ Añade, en términos ilustrativos la Sentencia, «la conclusión no puede ser otra, por razones de aplicación del principio constitucional de certeza y seguridad jurídica ... que la de que, para entender modificado el régimen de un beneficio de carácter temporal concedido correcta y específicamente como medida de fomento y de conformidad con una norma jurídica sectorial que no ha sido objeto de concreta derogación, es preciso que por la disposición derogatoria se determinen expresamente las condiciones de su modificación o supresión».

${ }^{86}$ RJ 1623.

${ }^{87}$ RJ 4981.

${ }^{88}$ Se trataba concretamente de dos Reales Decretos de 1976 y 1985 que eximían del pago de derechos aduaneros «para el pescado capturado por los buques nacionales aportados o vendidos a aquéllas por parte del socio español, dentro de los límites o cupos fijados por la Dirección general de Ordenación pesquera» y que el Acta de adhesión de España a las Comunidades Europeas obliga a eliminar en un plazo de siete años. Para el Tribunal Supremo, en efecto, las empresas no son portadoras de «meras expectativas» sino «de un derecho, en cuanto lo tienen acreditado para disfrutar del correspondiente cupo, sea en mayor o menor medida, con interdicción, desde luego, de toda arbitrariedad y aunque haya de fijarse preceptivamente todos los años»; de ahí la corrección de la pretensión de indemnización por privación de derechos formuladas por las empresas, porque, continúa el Tribunal Supremo, la responsabilidad por actos emanados del Poder Legislativo «no puede negarse cuando la Ley tiene un contenido expropiatorio de derechos o intereses patrimoniales legítimos, como ocurre en el presente supuesto, en el que hemos razonado, y debemos reiterar, la existencia de verdaderos derechos adquiridos para obtener los beneficios que elimina, durante un periodo de siete años, el artículo 168 del Acta de Adhesión del Reino de España a las Comunidades Europeas». Las pretensiones, señalan además las Sentencias, estarían avaladas «tanto por los principios de buena fe que debe inspirar la relación de la Administración con los particulares y de la seguridad jurídica, como por el equilibrio de prestaciones que debe existir entre una y otros en el desarrollo de relaciones».
}

${ }^{89}$ RJ 5024. 
sitos exigidos por la Administración, con arreglo a las normas de aplicación» ${ }^{90}$.

Este conjunto de Sentencias evidencian, en definitiva, cómo, ante un cambio normativo, el particular no sólo tiene derecho a la intangibilidad de los efectos ya consumados o agotados en aplicación de la disposición anterior, sino, también, a aquéllos que, aun no producidos, son inherentes al cumplimiento del presupuesto de hecho bajo la normativa anterior. El fundamento de esta tesis lo obtiene el Tribunal Supremo en las Sentencias citadas de la «aplicación del principio constitucional de certeza y seguridad jurídica ${ }^{91}$, y de «la responsabilidad por actos emanados del Poder Legislativo» ${ }^{92} y^{93}$. En realidad, las razones que, en estos supuestos, justifican la tutela del Derecho son las mismas que exponíamos en el apartado anterior; el problema radica en la propia delimitación del concepto de derecho adquirido; concepto que, probablemente, deba abrirse a estas situaciones jurídicas, abandonando, de esta forma, el estrecho reducto de los derechos por entero incorporados al patrimonio de su titular en el que siempre ha estado anclado en las antiguas doctrinas sobre la irretroactividad de las leyes. Con todo, ha de reconocerse que el expuesto no constituye un principio unánimemente aceptado no ya a nivel doctrinal ${ }^{94}$, sino, lo que es mas importante, por el propio Tribunal Constitucional que en su Sentencia 6/1983, de 4 de febrero ${ }^{95}$, se opone a esta tesis con los siguientes argumentos: «Algún autorizado sector doctrinal ha sostenido que en la exención de carácter general existe un derecho subjetivo al disfrute de la misma, que no puede ser suprimido, ni suspendido durante el tiempo de vigencia, de manera tal que la derogación de las

${ }^{90}$ Y continúa la Sentencia, «cuando el particular movido por dicha invitación de la Administración, acepta la misma y cumple los condicionamientos impuestos por aquélla, desarrollando la actividad por aquélla promovida, comprometiendo en tal empresa sus medios personales, finacieros y materiales, su confianza en la oferta de la Administración no puede verse defraudada por ésta posteriormente; pues amén de la correcta vinculación jurídico-negocial que toda oferta aceptada entraña, se infringiría con ello el principio doctrinal de la «confianza legítima» y el constitucional de la seguridad jurídica».

${ }^{91}$ Sentencias de 5.III.1993 (RJ 1623), 27.VI.1994 (RJ 4981) y 15.X.1998 (RJ 7913).

${ }^{92}$ Sentencias de 5.III.1993 (RJ 1623) y 27.VI.1994 (RJ 4981).

${ }^{93}$ Este principio puede, también, encontrar apoyo en la propia definición de derecho adquiridos que ofrece la D.T.2 ${ }^{\text {a }}$ de la Ley 29/1987, de 18.XII, del Impuesto sobre Sucesiones y Donaciones. «Por derecho adquirido se entenderá, dice la norma, tan sólo los que se acredite que, efectivamente, han comenzado a ejercitarse antes de la entrada en vigor de esta Ley, sin que la mera expectativa pueda reputarse derecho adquirido».

${ }^{94}$ Vid. C. Lozano Serano, Exenciones tributarias y derechos adquiridos, Tecnos, Madrid, 1988, en la que se defiende una posición contraria a la que resulta de las Sentencias citadas (en particular, pp. 83-115).

${ }^{95} \mathrm{La}$ Sentencia resuelve las cuestiones de inconstitucionalidad planteadas contra la D.T. $2^{a}$ b) del RDL de 20.VII.1979 que, en relación con la construcción de viviendas de protección oficial, transforma «la reducción del 90 por 100 durante veinte años en bonificación del 50 por 100 durante trece años». 
normas en que la exención hubiera sido concedida, no puede acarrear la pérdida de ese derecho, ni puede éste tampoco verse afectado por otras normas posteriores que supriman explícitamente las exenciones, porque en tal caso estaríamos en un supuesto de violación de derechos tributarios adquiridos. Sin embargo, a nuestro juicio, es más correcto entender que el llamado derecho a la exención o a la bonificación tributarias es simplemente un elemento de la relación jurídica obligacional, que liga a la Administración y al contribuyente y que, en el caso de la contribución territorial, no integra el derecho de propiedad, el de usufructo o el derecho real concreto que sea objeto de la contribución. El objeto de la exención -no pagar o pagar una cantidad inferior a la prevista con carácter general- es distinto del objeto sobre el que recae el derecho real. Por ello, no puede hablarse en puridad de un auténtico derecho a la bonificación tributaria o al mantenimiento del régimen jurídico-tributario de bonificación que pueda entenderse incorporado al patrimonio de los titulares del dominio -en nuestro caso a la propiedad de viviendas de protección oficial- y del que éstos puedan entenderse privados en virtud de una norma como el Real Decreto-ley 11/1979». La Sentencia cuenta, no obstante, con un importante voto particular de R. Gómez-Ferrer en el que sostiene que la norma sometida a juicio de constitucionalidad efectivamente «afecta a un beneficio fiscal otorgado por un plazo determinado, en virtud de un acto concreto, el acto de calificación» que, por razones que se explicitan en el propio voto, no debieran ser disponibles, como ha concluido la Sentencia, para el Legislador ${ }^{96}$. Desde luego, la decisión mayoritaria del Tribunal Constitucional es difícilmente entendible. No se comprende qué tiene que ver que el derecho adquirido a la bonificación tributaria no forme parte del derecho real de propiedad, como evidentemente ocurre, con la intangibilidad que deriva de su mera consideración de derecho adquirido, independiente de la propiedad, frente a la Administración. La cuestión no estaba en que el derecho adquirido formase o no parte del derecho de propiedad, sino en si realmente existía un derecho adquirido en el caso examinado.

No puede sino mantenerse la necesidad de una mayor atención a estas situaciones jurídicas que sin entrar de lleno en la noción clásica

\footnotetext{
${ }^{96}$ Indica el Magistrado Gómez-Ferrer «no puede ignorarse la trascendencia de la disposición transitoria cuestionada en cuanto reflejo del criterio de actuación que puede incidir en la confianza de los ciudadanos en el Estado. Es el Estado el que ha establecido un régimen legal especial para las viviendas de protección oficial, con sus ventajas y limitaciones. Los ciudadanos que han confiado en el Estado, y se han sometido voluntariamente a este régimen, han obtenido, de acuerdo con la legislación aplicable, un título jurídico concreto, que especifica los beneficios concedidos y limita -en la misma medida- el deber tributario durante el plazo de duración del beneficio otorgado».
} 
de derecho adquirido, no deben, desde luego, equipararse, como con frecuencia ocurre, a las simples expectativas, categoría de la que nos ocupamos a continuación.

\section{LAS EXPECTATIVAS}

\subsection{La falta de definición de una categoría de capital importancia}

La noción de expectativa posee una importancia capital, no sólo en el plano exclusivamente dogmático, sino, también, en el más concreto de la aplicación del Derecho, toda vez que la calificación de una situación jurídica como tal implica, en principio, el reconocimiento, en nuestro actual estado normativo, de la legitimidad de su modificación sin que ante ella su titular pueda oponer título alguno. Pocas categorías, sin embargo, tan escasamente analizadas como ésta, de la que el Tribunal Supremo ha afirmado en Sentencia de 28.V.200197, que «se trata de uno de esos decires usaderos que han cristalizado antes de ser entendidos .... y a los que se recurre para cerrar una cuestión cuando no se encuentran argumentos mas sólidos y, desde luego, sin plena conciencia de su significado». Acierta, sin duda, el Tribunal Supremo en su denuncia sobre la falta de precisión de una noción sobre la que cabalmente gira gran parte del conflicto entre interés privado e interés público que puede suscitarse con ocasión de la transformación del Derecho, y en su consiguiente llamada de atención sobre la necesidad de su estudio y prudente manejo. Sorprende, desde luego, el escaso interés que la categoría, que L. DUGUiT ya calificó como «precaria y incierta ${ }^{98}$, ha despertado en nuestra doctrina; en particular, en la del Derecho público ${ }^{99}$. Recientemente, P. Escribano COLLADO se ha ocupado de su examen definiendo la expectativa como «un derecho in fie$r i$, en formación, situación en la que un sujeto está en fase de consolidar todos los elementos, condiciones o grados previos requeridos por la ley para la existencia plena de un derecho, alguno de los cuales han sido ya realizados y existe incertidumbre sobre los restantes» ${ }^{100}$.

${ }^{97}$ RJ 7994.

${ }^{98}$ Traité de Droit Constitutionell, op. cit., p. 228.

${ }^{99}$ Y no sólo en la doctrina del Derecho público y en España. En Italia, y desde la óptica del Derecho civil, se viene, igualmente, llamando la atención sobre la indefinición de la figura. Vid. R. Nicolo («Voz» Aspettativa», p. 1), o A.C. PElOSI («Voz «Aspettativa», Nuovo Digesto delle Discipline privatische, I, Utet, Tutin, 1987, pp. 466 y ss.).

${ }^{100}$ Voz «Expectativa», Enciclopedia Jurídica Básica Civitas, 1995, Vol. II, p. 2997.

Con esta definición P. EsCRIBANO COLLADO, se aparta, y así lo reconoce expresamente, de la doctrina de F. DE CASTRO, quien rechaza la noción de expectativa con referencia al proceso de adquisición suscesiva de un derecho proponiendo la sustitución de la figura por la de «situaciones interinas» en las que expresamente engloba la «gran variedad de situaciones ju- 


\subsection{La necesaria diferenciación entre distintos tipos posibles de «expectativas»}

Aunque el concepto de expectativa está necesitado, como dice el propio Tribunal Supremo, «de una más madura reflexión» ${ }^{101}$; no obstante, el análisis de las muchas Sentencias en las que esta noción se convierte en la clave del razonamiento y fallo judicial, ofrece algunas conclusiones de interés.

Por lo pronto hay que advertir de que las expectativas que deben merecer nuestra atención son las que tienen relevancia o significación jurídica ${ }^{102}$. Pues bien, entre éstas puede diferenciarse de entrada, según resulta de la propia jurisprudencia, entre aquéllas que aluden a la consolidación de una determinada situación de hecho de la que han de derivar determinadas consecuencias jurídicas y las que, de otra parte, se refieren a la consolidación de una situación jurídica subjetiva. Como exponente de las primeras puede hacerse referencia, por ejemplo, a la situación de aquellos terrenos que no contando aún con la condición de solar, gozan, sin embargo, «de una vocación o expectativa inmediata de serlo», circunstancia que es tomada en consideración a efectos impositivos ${ }^{103}$. La expectativa viene, así, a constituir la previsión de la consecución de un estado de hecho, a la que el Derecho, anticipadamente, engarza determinadas consecuencias jurídicas; cómo ocurre, también, en las denominadas expectativas urbanísticas ${ }^{104}$. La

rídicas creadas por el Derecho para conservar en suspenso o interinamente el estado de cosas existente, entre tanto se determina cuál sea la situación definitiva, Derecho civil de España, op. cit., pp. 606-616. Otros autores participan, por el contrario, de la definición de la expectativa en términos similares a los ofrecidos por P. Escribano, Así, P.J. AZURZA Y Oscoz, «Sobre la naturaleza y disponibilidad de la posición de reservatario. Aportación a la teoría de la expectativa» RGLJ, Segunda época, T.XII, 1948, pp. 89 y 116; MAZEAUD Derecho civil, Parte I, Ediciones jurídicas Europa-América, Buenos Aires, 1976, pp. 224 y 5 o A. CARreTERo PÉreZ, «Los derechos adquiridos y la edad de jubilación de jueces y magistrados», op. cit., p. 756. Vid., también, sobre el tema las consideraciones efectuadas por J. ACEDO, «Retroactividad de las leyes», Revista Crítica de Derecho Inmobiliario, 1958, p. 223.

${ }^{101}$ Sentencia de 28.V.2001 (RJ 7994).

${ }^{102}$ La citada STS de 13.VI.2001 (RJ 7994) se ocupa de señalar que la distinción entre las expectativas indiferentes para el Derecho y las dotadas de protección jurídica cuenta con fundamento en la propia acepción del término según el Diccionario de la Real Academia de la Lengua, idea también destacada por P. Escribano Collado, (Voz «Expectativa», op. cit., ...). y que ya figuraba, también, en el Diccionario de Administración y Derecho de Escriche de 1874 en el que la expectativa aparecía definida en los siguientes términos: «cualquier esperanza de lograr alguna cosa, verificándose la oportunidad que se desea; el derecho y acción que uno tiene a conseguir alguna cosa en adelante, como empleo, oficio o herencia en que deba suceder ó que le toca a falta de poseedor» (op. cit., 936).

${ }^{103}$ Vid. STS de 13.VI.2001 (RJ 6722) con cita de otras muchas anteriores en el mismo sentido.

${ }^{104}$ Existe, en efecto, una importante corriente jurisprudencial que, en relación con la valoración de los terrenos no urbanizables objeto de expropiaciones no urbanísticas, vino considerando que este suelo «es susceptible de ser valorado por sus expectativas urbanísticas» 
presunción, en definitiva, de que el terreno pueda pronto integrarse en el proceso urbanizador, de que se modifique su naturaleza jurídica, se considera, pues, una circunstancia digna de valoración, una expectativa atendible por el Derecho, con efectos, en este caso, claramente favorables para el interesado, a diferencia del supuesto anterior en el que la expectativa se convierte en fundamento de una mayor carga impositiva. He aquí, en suma, dos supuestos, fruto, el primero, de la expresa previsión normativa y resultado, el segundo, de un principio jurisprudencial formulado en aplicación del Derecho, en los que las expectativas, consistentes no en un derecho en formación, sino en un proceso de transformación de la realidad, adquieren significación o relevancia jurídica.

Nuestro interés va a centrarse, sin embargo, en las expectativas que vienen a coincidir con un determinado status jurídico en favor de un administrado que, en muchas ocasiones, coincide, en efecto, con una posición jurídica en trance de conversión en un auténtico derecho siempre y cuando lleguen, realmente, a cumplirse el conjunto de requisitos o condiciones que el propio ordenamiento establece. De esta forma, las expectativas, y de ello da buena cuenta la jurisprudencia, terminan por abarcar todas aquellas situaciones que el Tribunal Supremo denomina «interinas» y que «el legislador protege de forma transitoria en tanto se produce su definitiva consolidación» ${ }^{105}$. En nuestra jurisprudencia termina por trazarse, en suma, una importante línea divisoria que, en un lado, coloca los derechos adquiridos, en tanto que, en el otro, situa todas las situaciones, de muy diversa naturaleza e intensidad, que en un proceso más o menos dilatado en el tiempo preceden al perfeccionamiento, a la adquisición del derecho. Los derechos adquiridos merecen, según esa misma jurisprudencia, el respeto del ordenamiento jurídico; no así, en cambio, las expectativas, cuya desaparición o alteración constituye, según reiterada doctrina jurisprudencial, un efecto inevitable del cambio de normas. Otra solución supondría, proclama reiteradamente el Tribunal Supremo, una petrificación o congelación del ordenamiento jurídico contraria al poder de innovación de toda norma y a los principios propios del Estado social $^{106}$.

El régimen jurídico de los funcionarios públicos constituye, probablemente, el mejor exponente de esta idea. En la jurisprudencia,

siempre que «éstas sean reales y resulten probadas en función de las diversas circunstancias del terreno, como la proximidad a suelo urbano y los servicios e infraestructuras existentes» Vid., por todas, STS de 27.II.2001 (RJ 2633) con abundante cita de otras muchas anteriores en la misma línea. La STS de 22.VI.1999 (RJ 5737) resume las modificaciones normativas que se han producido en esta materia.

${ }^{105}$ STS de 28.V. 2001.

${ }^{106}$ Vid., por todas, la Sentencia de 23.II.1996 (RJ 9497). 
incluida la del propio Tribunal Constitucional, es habitual la referencia al hecho de que «... el funcionario que ingresa al servicio de la Administración Pública se coloca en una situación jurídica objetiva, definida legal y reglamentariamente, y por ello modificable por uno $\mathrm{u}$ otro instrumento normativo .... sin que consecuentemente pueda exigir que la situación estatutaria quede congelada en los términos en que se hallaba regulada al tiempo de su ingreso» ${ }^{107}$. Este principio, absolutamente consolidado en nuestro ordenamiento jurídico sobre la base dogmática de las relaciones de especial sujeción ${ }^{108}$, ha servido de fundamento a los Tribunales para la desestimación, entre los casos más conocidos, de los muchos recursos interpuestos en demanda de indemnización por el adelanto de la edad de jubilación ${ }^{109}$, la transformación del régimen de incompatibilidades ${ }^{110}$, la supresión del derecho de consorte ${ }^{111}$ o la modificación del sistema de seguridad social y derechos pasivos ${ }^{112}$. En todos estos casos, así como en otros muchos, va a negarse la existencia de auténticos derechos del funcionario público y a estimarse paralelamente que la jubilación a la edad establecida en el momento en el que se ingresó en la función pública, determinado sistema de compatibilidades, las pensiones previstas y, en general, la preservación del estatuto jurídico del que se gozó en algún momento de la vida funcionarial no constituyen sino «meras» o «simples» expectativas sujetas a posibles alteraciones

107 SSTC, entre otras, 99/1987, de 11.VI, 129/1987, de 16.VII, 70/1988, de 19.IV, 178/1989, de 2.XI, 41/1990, de 15.III., 100/1990, de 30.V.

${ }^{108}$ Vid., sobre el tema, las importantes monografías de R. GARCía MACHO, Las relaciones de especial sujeción en la Constitución española, Tecnos, Madrid, 1992, I. LASAGABASTER HerrarTe, Las relaciones de sujeción especial, Civitas, Madrid, 1994 y M. LóPEz BENíTEZ: op. cit.

${ }^{109}$ SSTC 108/1986, de 29.VII, 99/1987, de 11.VI y 70/1988, de 19.IV.

Son muy numerosas las ocasiones en las que el Tribunal Supremo ha defendido idéntico principio. A título puramente ilustrativo, pueden verse las Sentencias de 26.XI.1999 (RJ 3196), 29.XI.1999 (RJ 3198), 30.XI.1999 (RJ 3201/2000), 9.XII.1999 (RJ 3270/2000).

${ }^{110}$ SSTC 178/1999, de 2.XI, 42/1990, de 15.III y 67/1990, de 5.IV.

El criterio se reproduce en numerosas Sentencias del Tribunal Supremo. Por ejemplo, en las de 27.VI.1997 (RJ 4748) o 8.VII.1999 (RJ 6717).

${ }^{111}$ Son muy abundantes las Sentencias del Tribunal Supremo que resuelven los muchos recursos interpuestos contra la supresión, por el RD 895/1989, de 14.VII, del derecho de consorte como criterio para la provisión de puestos de trabajo en determinados cuerpos de funcionarios. Vid., por todas, la Sentencia de 9.VI.1992 (RJ 4794).

${ }^{112}$ Las reformas en esta materia han generado, también, especial conflictividad. En todas las ocasiones en las que han tenido ocasión de pronunciarse con origen en normas diversas, tanto el Tribunal Constitucional (Sentencias 65/1987, de 21.V, 127/1987, de 16.VII, 134/1987, de 21.VII, 208/1988, de 10.XI, 65/1990, de 5.IV, 66/1990, de 5.IV, 97/1990, de 24.V, 100/1990, de 30.V y 75/1991, de 11.IV) como el Tribunal Supremo (Sentencias, entre otras, de 24.X.2000, RJ 10369, con abundante cita de otras anteriores en la materia, o 28.V.2001, RJ 7994) han negado los alegados derechos de los funcionarios al mantenimiento del régimen establecido en un momento dado. 
normativas ${ }^{113}$. En conclusión, los funcionarios públicos, según el propio ordenamiento, sólo tienen derecho al mantenimiento del contenido de la función a desarrollar, así como a las remuneraciones económicas que hubiesen consolidado ${ }^{114}$. Siendo ello así, desde luego, en el estado actual de nuestro Derecho, no debe, sin embargo, pasarse por alto la importante afirmación del Tribunal Constitucional ${ }^{115}$ que, en relación con el adelanto de la edad de jubilación, señalaría que «esa modificación legal origina una frustración de las expectativas existentes y en determinados casos perjuicios económicos que pueden merecer algún género de compensación», pronunciamiento, sobre el que volveremos, de oscuro significado y que no podía sino merecer los juicios más encontrados.

La idea de la expectativa en referencia al proceso de formación gradual de un derecho que eventualmente puede verse truncado por un cambio normativo, se ilustra también con claridad en otros muchos ámbitos; en general, en relación con todos los regímenes propios del derecho de propiedad o el de libertad de empresa en donde se reconoce al poder público un amplio poder de conformación de su ejercicio. Así acontece, por citar algunos de los muchos supuestos que pueden extraerse de esa jurisprudencia, en relación al régimen de instalación y explotación de máquinas recreativas ${ }^{116}$, de las licencias de autotaxi $^{117}$ o de las actividades clasificadas ${ }^{118}$.

Ahora bien, existen ocasiones, dentro de la extremada variedad que el Derecho ofrece en esta materia, en las que esas situaciones definidas como expectativas no aluden exactamente a un derecho in fie$r i$; no se refieren, en puridad, a la situación en la que se encuentra un sujeto que, de no producirse un cambio normativo, alcanzará la consolidación de un derecho una vez se complete el presupuesto de hecho previsto en la norma; son, en términos afirmativos, los supuestos en los que la expectativa viene sencillamente a coincidir con el simple

${ }^{113}$ Quizá interese señalar que esta doctrina, desarrollada en el ámbito de la función pública, se viene aplicando, también, al régimen de aquellos colectivos que, también, disponen de un estatuto normativamente establecido. Vid., por ejemplo, STS de 18.IX.1997 (RJ 6917) en relación con los Agentes de cambio y bolsa o la STC 42/1986, de 10.IV en relación con el personal del Colegio oficial de Psicólogos.

${ }^{114}$ Un desarrollo de esta última cuestión puede encontrarse en L. ORTEGA ÁLVAREZ, Voz «Derechos adquiridos de los funcionarios». Enciclopedia jurídica Civitas, Vol. II, op. cit., pp. 2381 y 2 .

Las Sentencias que pueden citarse en apoyo de este principio de respeto a los derechos económicos y al mantenimiento de las condiciones de trabajo son muy abundantes. Así, por ejemplo, 17.III.1997 (RJ 1902), 21.III.1997 (RJ 1933), 11.IV.1997 (RJ 2670) o 27.X.1999 (RJ 2007/2000).

115 Sentencias 108/1986, de 29.VI, 99/1987, de 11.VI y 70/1988, de 19.IV.

116 STS de 29.I.1998 (RJ 1103).

117 STS de 6.V.1985 (RJ 4751).

${ }^{118}$ SSTS de 30.V.1985 (RJ 3192), 11.X.1988 (RJ 7475). 
deseo de estabilidad, de mantenimiento de un determinado régimen jurídico; en eso radica, justamente, el interés de quien la invoca; la expectativa ya no es, vista desde la perspectiva del ciudadano, un título a esgrimir en defensa, por ejemplo, de un futuro derecho a la jubilación o a una pensión de las características de las que, en determinado momento, se esperó; bajo esta otra especie de expectativa lo que el administrado reivindica es la intangibilidad del régimen jurídico existente en determinado momento, el interés en su mantenimiento con el conjunto de consecuencias, favorables o adversas, que le sean inherentes. No se está, se podría decir en términos, quizás, más gráficos, luchando por derechos futuros; se están defendiendo posiciones de presente, la permanencia de normas en base a las cuales se han tomado decisiones, se han emprendido actuaciones y que, si desaparecen de manera imprevista, pueden causar evidentes perjuicios a quienes en ellas confiaron. Es, sin duda, en el ámbito de la regulación de la economía, regulación flexible y cambiante donde las haya ${ }^{119}$, donde se manifiesta con mayor nitidez esa necesaria o al menos conveniente defensa de las posiciones jurídicas individuales identificadas, en último término, con una pretensión de estabilidad del Derecho en cuya aplicación se actúa y que ha servido de fundamento a decisiones en las que no sólo pueden estar comprometidos los intereses de quienes las han tomado, sino también el correcto funcionamiento de la economía y, por consiguiente la satisfacción de los intereses generales. Es justamente la protección de estas expectativas la que con mayor intensidad se reivindica por la doctrina de nuestro tiempo engarzándolas con el principio de seguridad jurídica traducido en términos de confianza en la estabilidad del Derecho y de previsibilidad de sus alteraciones. Antes de ahondar, sin embargo, en si, efectivamente, estas expectativas, y en general todas las situaciones incardinables en esta categoría, son o no dignas de protección jurídica, conviene advertir de que las dos especies de expectativas apuntadas pueden coexistir en una situación dada en la medida en que la pretensión de estabilidad de determinado régimen jurídico puede llevar aparejada la consecución de concretos derechos. Ahora bien, a la hora de reflexionar sobre la posible protección del Derecho a estas situaciones jurídicas que no coinciden con un de-

\footnotetext{
${ }^{119}$ Es muy numerosa la bibliografía que, desde una u otra perspectiva, se ha ocupado de destacar las singularidades de las normas que rigen la intervención pública en la economía y la crisis que, en su ámbito, sufren no pocas categorías, cuestiones ya destacadas por J.L. VILLAR PALASí, Derecho Administrativo. Introducción y Teoría de las normas, Universidad de Madrid, Madrid, 1968; en especial, pp. 345-9 y del que, más recientemente se ha ocupado, entre otros, S. MarTín-ReTorTiLlo, Derecho Administrativo económico I, La Ley, Madrid, 1988; en particular, pp. 392 y ss.). Desde la óptica del Derecho privado, vid. L. DíEZ-PICAZo, y V. MonTEs, Derecho privado y sistema económico, Departamento de Derecho civil, Universidad Autónoma de Madrid, 1979, pp. 5-17.
} 
recho perfecto, importa, por cuanto ha de verse a continuación, tener en cuenta la distinción apuntada.

\section{3. ¿Merecen las expectativas la tutela del Derecho?}

La pregunta, formulada en términos amplios, está necesitada, en cambio, de respuestas matizadas, de formulaciones adecuadas a la diversidad de las situaciones jurídicas sobre las que, en cada caso, se efectúa el juicio. El necesario relativismo que debe presidir cualquier intento de elaboración de una teoría sobre la protección de las expectativas en Derecho administrativo no invalida, sin embargo, la reflexión general sobre un tema del que puede afirmarse, sin riesgo de errar, que está por elaborar. Existen, sin duda, valiosos y recientes estudios que abordan su tratamiento con ocasión, generalmente, del análisis del principio de confianza legítima, ampliamente desarrollado, como es sabido, por el Tribunal de Justicia de las Comunidades Europeas; falta, sin embargo, un estudio comprensivo que diferencie adecuadamente entre los distintos tipos de expectativas existentes y que abunde en los diferentes títulos constitucionales que, en su caso, pueden fundamentar su posible protección. Desde luego, son ya muchas las voces que se han alzado en defensa, sobre todo en el ámbito del cambiante Derecho económico, de una mayor protección de las expectativas consistentes en el mantenimiento de un determinado régimen jurídico a cuyo amparo tomaron sus decisiones los agentes económicos. Particularmente ilustrativas resultan al respecto las rotundas consideraciones de L. LAVILLA, en el sentido de que estas expectativas «no debieran ser cancelables - como parece admitirse que lo sean-por ulteriores decisiones del legislador, al hilo normalmente de los azares políticos o de las circunstancias coyunturales « y respecto de las que si «no cabe apelar a la seguridad jurídica en términos de certeza, sí puede ser coherentemente invocada en términos de previsibilidad, de cálculo razonable sobre el que los ciudadanos toman sus decisiones y que no ha de verse frustrado - por mucho que sea el legislador quien lo frustre- sin que falle la garantía de seguridad jurídica y se instale un contraprudecente clima de inquietud desorientada» ${ }^{120}$. Resulta fá-

${ }^{120}$ Seguridad jurídica y función del Derecho, op. cit., en particular, p. 56. En este mismo sentido se expresan otros autores como, por ejemplo, F. CASTILlO BlANCO, La protección de confianza en el Derecho Administrativo (op. cit., pp. 97-100), J.J. SANTAMARÍA IBEAS, Los valores superiores en la jurisprudencia del Tribunal Constitucional. Libertad, justicia, igualdad y pluralismo político, Ed. Dykinson, Madrid, 1997, p. 77, G. PECES-BARBA, «La Seguridad Jurídica desde la Filosofía del Derecho». Anuario de Derechos humanos. Facultad de Derecho de la Universidad Complutense, núm. 6, 1990, pp. 218, 224 y 5, F. SAINZ MORENO, Voz «Seguridad jurídica», Enciclopedia Jurídica Civitas, 1995, Vol. IV (op. cit., pp. 6108, 6116 y 7), V. MAGARIÑOS 
cil suscribir cuanto afirma L. LAVILLA; de hecho, el propio Tribunal Constitucional se ha referido a la estabilidad del Derecho y la previsibilidad de su cambio como parte integrante de la seguridad jurídica, aunque, ciertamente, no pueda considerarse una idea de nuestros días ${ }^{121}$. El problema no se resuelve, sin embargo, con una afirmación de principio. Aceptada la necesaria protección de las expectativas, el centro de la cuestión se desplaza, sin duda, al terreno de su concreción; ámbito en el que, al menos, han de resolverse dos cuestiones fundamentales: en primer término, la propia delimitación de las expectativas protegibles - ¿han de serlo todas?, ¿̇sólo algunas de ellas definidas por su especial naturaleza?, ¿̇la protección de la expectativa depende, por el contrario, de su mayor o menor cercanía a la consolidación de un derecho, de un criterio, por consiguiente, puramente cuantitativo?-. En segundo lugar, la determinación de los mecanismos necesarios para la articulación de la tutela. En el sustrato de ambas cuestiones late, sin duda, una tercera de importancia capital: la de cuáles son, si es que existen, los fundamentos constitucionales de la protección. Aunque parecería lo lógico comenzar por la última de las cuestiones propuestas, veamos, primero, el estado de la cuestión en el Derecho vigente, es decir, qué establecen al respecto nuestras normas, para indagar, más tarde, el posible fundamento constitucional de esa tutela.

BLANCO, La seguridad jurídica y el Estado de Derecho en España, Real Academia de Legislación y Jurisprudencia, Sevilla, 1993, pág.16 o A. SERRANO DE TRIANA, La función de la seguridad jurídica en la doctrina del Tribunal Constitucional (op. cit., p. 1244).

Interesa notar, sin embargo, que no todos los autores que se han pronunciado sobre el contenido de la seguridad juídica se han manifestado de manera tan rotunda en su consideración de que este principio exija cierta estabilidad en el Derecho y una relativa capacidad de predicción por el ciudadano de los cambios normativos. Así, para F. GARRIDO FALLA, la seguridad jurídica, «principio genérico que se diluye casi exclusivamente en el resto de los principios enumerados en el número 3 del artículo 9» consiste en «la certeza del Derecho, que intrinsecamente debe ser claro y preciso, y, formalmente publicado» y en la regla de la irretroactividad y la jerarquía normativa (Comentarios a la Constitución, Civitas, Madrid, 1980, p. 122). J. LEGUINA VILLA, por su parte, se refiere, como parte integrante de la seguridad jurídica, a «la previsibilidad de las consecuencias jurídicas derivadas de las propias acciones o de las conductas de terceros» sin mayor precisión, «Principios generales del Derecho y Constitución», RAP núm. 114, 1987, p. 34. Más recientemente, L. GARCíA LUENGO ha llamado la atención sobre las «grandes precauciones» con las que ha de actuarse a la hora de entender la garantía de la seguridad jurídica «como una garantía de estabilidad», El principio de protección de la confianza legítima en el Derecho Administrativo, Civitas, Madrid, 2002, p. 193.

${ }^{121}$ Particularmente ilustrativas resultan en este sentido las consideraciones de G. RADBRUCH, que entre las cuatro condiciones que requiere la realización de la seguridad jurídica se refiere, justamente, a la estabilidad del Derecho. «Finalmente, el Derecho positivo -si se quiere garantizar la seguridad jurídica- no debe hallarse expuesto a cambios demasiados frecuentes, no debe hallarse a merced de una legislación incidental, que dé todo género de facilidades para troquelar cada caso concreto en forma de ley ...», Introducción a la Filosofía del Derecho. $4^{a}$ edición en castellano de la alemana publicada en 1948, Fondo de Cultura Económica, Mexico, 1974, p. 40. 
La protección de las expectativas no es, ni mucho menos, ajena a nuestro Derecho. Existen ocasiones en las que el ordenamiento jurídico establece expresamente la tutela de esas situaciones jurídicas que vienen a coincidir con los estados o fases previas de formación de un derecho ${ }^{122}$, de otra parte, puede considerarse regla general la presencia de un régimen transitorio en el conjunto de disposiciones que disciplinan la actividad de los distintos sectores económicos; regímenes con los que se intenta ordenar el tránsito de una normativa a otra en respuesta, justamente, a las expectativas creadas en aplicación de la que se deroga y cuya importancia ha sido ponderada tanto por la doctrina ${ }^{123}$, como por la jurisprudencia del Tribunal Supremo ${ }^{124}$ e, incluso, la del propio Tribunal Constitucional ${ }^{125}$. Si omitimos el detalle de esos régimenes, puede afirmarse que, por lo general, se concretan en el establecimiento de un principio de respeto a las situaciones jurídicas creadas en aplicación de la norma anterior, en una declaración de pervivencia transitoria de la normativa derogada, acompañada, si es necesario, del estableci-

${ }^{122}$ Aunque no se pueden considerar que sean, desde luego, mayoritarios, no son infrecuentes los supuestos en los que el Derecho dispensa expresamente su protección a las expectativas. Por ejemplo, la D.T. 1.3 del RD 843/1976, de 18.III, del Reglamento general del mutualismo administrativo, establece: «los socios y beneficiarios de las Mutualidades integradas, sean o no funcionarios del Estado, conservarán los derechos adquiridos o en curso de adquisición en relación con las prestaciones vigentes en la Mutualidad respectiva el 31 de diciembre de 1973», la Ley catalana 22/1998, de 30.XII, por la que se aprueba la Carta municipal de Barcelona, establece en su artículo 61.6 que «los funcionarios y personal laboral que sean incorporados a las plantillas de los consorcios y entidades a los que se refiere este artículo conservarán todos los derechos adquiridos de que gozaban en el momento de la incorporación, incluidas las expectativas de promoción y movilidad, y los demás inherentes a su situación funcionarial o laboral».

Por su parte, el RD 658/2001, de 22.VI, del estatuto general de la Abogacía española, declara que «las situaciones creadas y los derechos adquiridos con arreglo al régimen anteriormente en vigor serán respetados».

${ }^{123}$ Vid., al respecto, L. LaVILla Alsina, Seguridad jurídica y función del Derecho (op. cit., en particular, p. 58) y F. CASTILLO BLANCO, «El principio de confianza legítima y el ordenamiento jurídico español», op. cit., pp. 37 y 42 y La protección de confianza en el Derecho Administrativo, op. cit., pp. 331-368 o las más antiguas de J.M. MANRESA, Comentarios al Código civil español T. I, (op.cit., p. 159) o M. Albadalejo, (Dir): Comentarios al Código civil y Compilaciones forales, T. I, Revista de Derecho privado, Madrid, 1978, p. 76. En la doctrina alemana, R. STOBER, (Derecho Administrativo económico, Ministerio para las Administraciones Públicas, Madrid, 1992, p. 87) y en la italiana G. GrotTanelli DE’ Santi, (Voz «Diritto Transitorio», pp. 1-3).

${ }^{124}$ Vid., por todas, la Sentencia de 27.I.1990 (RJ 562), así como la más reciente de 24.I.2000 (RJ 10107).

${ }^{125}$ También su jurisprudencia ha llamado la atención sobre la necesidad de que las nuevas normas que incidan en situaciones jurídicas individuales cuenten con «unas cautelas de transitoriedad que reglamenten el ritmo de la sustitución de uno por otro régimen jurídico» (Sentencia 27/1981, de 20.VII), periodo transitorio con cuya limitación temporal el Tribunal se muestra de acuerdo al estimar que «ocasiona indudables perturbaciones y coloca algún punto de duda sobre el principio de seguridad jurídica también consagrado y reconocido en el art. 9 de la Constitución» (Sentencias 42/1986, de 10.IV y 386/1993, de 23.XII). 
miento de un plazo de adaptación al nuevo Derecho en el que no es infrecuente, además, que se prevea una amplia política de incentivos y ayudas públicas a los sujetos que ven transformado el régimen jurídico de su actividad. De este modo ocurre en el Derecho de las Telecomunicaciones $^{126}$ y en el de la Energía eléctrica ${ }^{127}$, en el de los Hidrocarbu$\operatorname{ros}^{128}$ y la Banca ${ }^{129}$; y, también, en el Derecho de la Industria ${ }^{130}$, los Se-

${ }^{126}$ Vid., por ejemplo, el artículo 16.11 de la Ley 11/1998, de 24.IV, General de Telecomunicaciones faculta al Ministerio de Fomento en relación con la modificación de las condiciones de las licencias individuales de telecomunicaciones y la D. T. $1^{\text {a }}$, respecto de los títulos para la prestación de servicios y utilización del dominio público radioeléctrico otorgados bajo la vigencia de la anterior normativa.

${ }^{127}$ Así, las Disposiciones Transitorias de la Ley 54/1997, de 27.XI, del Sector eléctrico, reconocen «a quienes a la entrada en vigor de la presente Ley sean titulares de instalaciones autorizadas» el derecho a "continuar en el ejercicio de sus actividades dentro de los términos de la autorización», de la misma forma en que se les reconoce el mantenimiento de los beneficios de que disfruten regulados por la Ley 82/1980, de 30 de diciembre, y se determinan incentivos para lograr la pronta adaptación de esas instalaciones al nuevo régimen legal.

Vid., también, en esta materia el RD 2018/1997, de 26.XII, por el que se aprueba el Reglamento de puntos de medida de los consumos y tránsitos de energía eléctrica, en el que se establece un largo calendario temporal para la adaptación y sustitución de aparatos, asi como el también RD 1955/2000, de 1.XII, por el que se regulan las actividades de transporte, distribución, comercialización, suministro y procedimientos de autorización de instalaciones de energía eléctrica, en el que se reconoce a los transportistas que a la entrada en vigor de la Ley 54/1997, del Sector Eléctrico, fueran titulares de instalaciones autorizadas podrán continuar en el ejercicio de sus actividades dentro de los términos de la autorización, derecho que, también, se reconoce a generadores y distribuidores.

${ }^{128}$ Me remito al respecto a cuanto disponen las Disposiciones transitorias de la Ley 34/1998, de 7.X, por la que se regula el sector de los Hidrocarburos y en las que, en general, se mantiene la vigencia del régimen derogado respecto de ciertas actividades en funcionamiento a la entrada en vigor de la Ley; en particular, se establece que los permisos de investigación. concesiones de explotación y autorizaciones otorgadas al amparo de la Ley 21/1974, de 27 de junio, sobre régimen jurídico de la investigación y explotación de hidrocarburos o anteriores, se regirán por dicha Ley, salvo manifestación expresa de los titulares, de su deseo de acogerse a la regulación que para dichos permisos y concesiones establece la presente Ley.

${ }^{129}$ Entre la profusa normativa existente en la materia, pueden verse, a título de ejemplo, las Disposiciones Transitorias de la Ley 26/1988, de 29.VII, de Disciplina e Intervención de las Entidades de crédito; Ley 13/1985, de 25.V, de Coeficientes de inversión, recursos propios y obligaciones de información de los intermediarios financieros; del RDLeg 1298/1986, de 28.VI, de adaptación del Derecho vigente en materia de Entidades de crédito al de las Comunidades Europeas; Ley 24/1988, de 28.VII, del Mercado de Valores, Ley 3/1994, de 14.IV, de adaptación de la Legislación española en materia de Entidades de crédito a la $2^{\text {a }}$ Directiva de coordinación bancaria y se introducen otras modificaciones relativas al sistema fnanciero; $\mathrm{RD}$ 1245/1995, de 14.VII, sobre creación de bancos, actividades transfronterizas y otras cuestiones relativas al régimen jurídico de las Entidades de crédito.

${ }^{130}$ Así, por ejemplo, la Disposición Transitoria $1^{\text {a }}$ de la Ley 21/1992, de 16.VII, de Industria establece que «las entidades concesionarias o reconocidas para la inspección de instalaciones industriales, existentes a la entrada en vigor de la presente Ley, podrán seguir actuando hasta la terminación del plazo de concesión o autorización o, si éste no existiera, durante un período de cinco años a contar desde la fecha de publicación de esta Ley».

Vid., también, $\mathrm{D}^{\circ}$. T ${ }^{\mathrm{a}} .1^{\text {a }}$ del RD 2200/1995, de 28.XII, del Reglamento de Infraestructura para la Calidad y la Seguridad industrial. 
guros $^{131}$, el Transporte ${ }^{132}$ y, por supuesto, en la normativa tributaria y fiscal ${ }^{133}$. En definitiva, allí donde la expectativa se cifra en la confianza en la estabilidad del régimen jurídico bajo el que se viene actuando, el Derecho es, en el común de los casos y con la previsión de un régimen transitorio, sensible a su protección, armonizando, de este modo, el reconocimiento del poder de innovación que toda norma comporta con la necesaria atención a las situaciones jurídicas afectadas por ella.

Ahora bien, ¿qué ocurre en los supuestos en los que la norma carezca de Derecho transitorio o en los que, aun contando con él, se estime insuficiente desde el punto de vista de la protección debida a determinadas expectativas? La respuesta parece clara. En estos casos, se habrán de poner en marcha los mecanismos de control propios del Estado entre los que, desde luego, ha de jugar un papel relevante el juicio de constitucionalidad de las leyes en el que, lógicamente, habrá de atenderse a las circunstancias particulares de cada caso, como el propio Tribunal Constitucional se ha encargado de recordar ${ }^{134}$. Será, entonces, cuando haya de plantearse el posible fundamento constitucional de la protección de estas situaciones jurídicas. Si esta protección efectivamente existe, parece obvio que operado el cambio normativo que vulnere la situación protegible y causado, pues, el perjuicio, habrán de aplicarse los necesarios mecanismos reparadores del daño generado.

Llegados a este punto, puede afirmarse, en concordancia no sólo con lo reseñado por la doctrina, sino con lo establecido por la jurisprudencia, tanto del Tribunal Supremo ${ }^{135}$ como del Tribunal Consti-

${ }^{131}$ Vid. Disposiciones Transitorias de la Ley 30/1995, de 8.XI, de Ordenación y Supervisión de los Seguros Privados.

${ }^{132}$ La Ley 16/1987, de 30.VII, de Ordenación de los Transportes terrestres, en el que, quizá, sea el aspecto más importante de su amplio régimen transitorio, reconoce a los actuales concesionarios de servicios regulares de transporte de viajeros un derecho de opción «entre mantener sus vigentes concesiones, en cuyo caso a medida que se vayan cumpliendo veinticinco años desde la fecha en que fueron otorgadas las mismas, la Administración irá procediendo al rescate de las mismas según la legislación vigente cuando fueron otorgadas sin que dichos concesionarios tengan ningún tipo de preferencias en el procedimiento que en su caso se lleve a cabo para seleccionar un nuevo prestatario» o sustituir las concesiones por las reguladas en la Ley en los términos en ella misma establecidos.

${ }^{133}$ El Derecho en esta materia es muy abundante. A título de ejemplo pueden verse las Disposiciones Transitorias de la Ley 61/1978, de 27.XII, del Impuesto de Sociedades.

${ }^{134}$ Vid. SSTC 173/1996, de 31.X.

${ }^{135}$ La Sentencia de 27.I.1990 (RJ 562) establece expresamente que «los principios de buena fe, seguridad jurídica e interdicción de la arbitrariedad proclamados en el artículo 9 de la Constitución obligan a otorgar protección a quienes legítimamente han podido confiar en la estabilidad de ciertas situaciones jurídicas regularmente constituidas en base a las cuales pueden haberse adoptado decisiones que afecten no solo al presente sino también al futuro condicionando éste ..... De aquí que lo que rotundamente no puede aceptarse es que una norma, ni reglamentaria ni legal, produzca una brusca alteración en una situación regularmente constituida al amparo de la legislación anterior, desarticulando por sorpresa una situación en cuya perdurabilidad podía legitimamente confiarse». 
tucional ${ }^{136}$ y también del Tribunal de Justicia de las Comunidades Europeas, que el principio de seguridad jurídica, ha de ser concebido, en una de sus muchas facetas, en términos de estabilidad de la norma y de previsibilidad de su alteración; en términos, puede también señalarse con apoyo en toda esa jurisprudencia comunitaria ${ }^{137}$, expresamente acogida por el Tribunal Supremo, de confianza legítima; principio que, como señala su Sentencia de 16.V.2000138, «cuando menos, obliga a responder en el marco comunitario de la alteración (sin conocimiento anticipado, sin medidas transitorias suficientes para que los sujetos puedan acomodar su conducta económica y proporcionada al interés público en juego, y sin las debidas medidas correctoras o compensatorias) de las circunstancias económicas habituales y estables, generadoras de esperanzas fundadas de mantenimiento»; aunque, como dice la propia Sentencia, el principio no garantiza, desde luego, «a los agentes económicos la perpetuación de la situación existente, la cual puede ser modificada en el marco de la facultad de apreciación de las instituciones comunitarias, ni les reconoce un derecho adquirido al mantenimiento de una ventaja» ${ }^{139}$. Con este principio se trata, en definitiva, de proscribir el cambio normativo imprevisto y ausente de medidas transitorias que cause pérdidas irremediables a los operadores que se encuentren en una situación especial respecto del resto, cuando han actuado con diligencia y buena $\mathrm{fe}^{140}$. Cual sea el funda-

136 Particularmente significativa ha de considerarse en este sentido la Sentencia 173/1996, de 31.X, en la que con cita de otras anteriores en la misma línea se señala que el artículo 9.3 de la Constitución, protege «la confianza de los ciudadanos, que ajustan su conducta económica a la legislación vigente, frente a cambios normativos que no sean razonables ni previsibles, ya que la retroactividad posible de las normas tributarias no puede trascender la interdicción de la arbitrariedad».

${ }^{137}$ En la obra de E. GUICHOT REINA, La responsabilidad extracontractual de los poderes públicos según el Derecho comunitario (Tirant lo blanch, Valencia, 2001, pp. 355-358) puede encontrarse una síntesis y comentario a esa jurisprudencia.

${ }^{138}$ RJ 5487.

139 Otras muchas Sentencias recogen esta misma doctrina. Así, SSTS de 13.II.1997 (RJ 978), 18.IX.1997 (RJ 6917), 18.XII.1999 (RJ 10070).

${ }^{140}$ Sobre este principio en el Derecho comunitario pueden verse, entre otros, los estudios de R. GARCía MACHO, «Contenido y límites del principio de confianza legítima: estudio sistemático en la jurisprudencia del Tribunal de Justicia», REDA, núm. 56, 1987, pp. 557-571; M.A. HERMITTE, «Spéculateurs et technocrates. De la non-rétroactivité des lois à la confiance légitime», Revue Trimiestrelle de Droit Européen 1984, pp. 455-463; F. HubEAU, «Le principe de la protection de la confiance légitime dans la jurisprudence de la Cour de justice», $\mathrm{Ca}$ hiers de Droit européen, 1983, pp. 143-162; M. LETEMENDIA, «Le principe de non rétroactivité en droit communautaire - Comparaison avec le droit anglais», Cahiers de Droit européen, 1977, pp. 518-570; F. LAMOUREUX, «The retroactivity of Community acts in the case law of the Court of justice», Common Market Law Review, 1983, pp. 269-296; E. SHARPSTON, «Legitimate expectations and economic reality», European Law Review, 1990, pp. 103-160; P. TAVERNIER, «Le juge communautaire et l'application dans le temps des règlements C.E.E».Annuaire français de droit international, 1976, pp. 169-206; E. VALLEJO LOBETE, «El respeto a la confianza legítima: importancia de este principio general del Derecho en el Derecho comu- 
mento del principio de confianza legítima, cuales sus relaciones con otro principio de gran arraigo en nuestro Derecho y con el que, sin duda, guarda estrecho parantesco, el principio de buena $\mathrm{fe}^{141} \mathrm{y}$, en fin, la determinación misma de su rango constitucional en cuanto expresión de la seguridad jurídica ${ }^{142}$, son cuestiones extremadamente sugerentes que no podemos abordar en estas páginas. En lo que aquí concierne, basta con destacar que, dándose las condiciones que según la propia jurisprudencia comunitaria determinan su aplicación, esto es, la existencia, no de cualquier tipo de convicción psicológica en el sujeto afectado sobre la permanencia del Derecho, sino la surgida de signos externos generados por el propio Poder público, los daños producidos por el cambio normativo imprevisto y adoptado sin las necesarias cautelas, habrán de ser debidamente indemnizados ${ }^{143}$; principio mayoritariamente aceptado en la doctrina de nuestros días aunque ha de reconocerse, desde luego, la existencia de opiniones discrepantes $^{144}$.

nitario» Gaceta Jurídica de la CE, B-27, pp. 2-9; D. WAELBROECK, «Le principe de la non-retroactivité en droit communautaire à la lumière des arrêts isoglucose» Revue Trimiestrelle de Droit Européen, 1983, pp. 363-392. Entre nosotros, hay que citar las monografías F. CASTILLO BlANCO, La protección de confianza en el Derecho administrativo, op. cit.; en particuar, pp. 163-199, sobre la jurisprudencia comunitaria; más recientemente E. GUICHOT REINA, La responsabilidad extracontractual de los poderes públicos según el Derecho comunitario, op. cit.

${ }^{141} \mathrm{Vid}$. al respecto las consideraciones efectuadas por F. CASTILlo BLANCO, La protección de confianza en el Derecho Administrativo, op. cit., pp. 255-276), sin olvidar la ya clásica y fundamental obra en la materia de J. GonZÁLEZ PÉREZ, El principio general de la buena fe en el Derecho Administrativo, Civitas, Madrid, 1983.

${ }^{142}$ La vinculación de la protección de la confianza legítima con el principio de seguridad jurídica es destacada por la generalidad de los autores que se han acercado a su estudio. Así lo hace, en términos que ya se han señalado, L. LaVILLA, Seguridad jurídica y función del Derecho (op. cit., en particular, p. 56), F. CASTILlO BLANCO, quien lo sitúa «entre los principios asociados a la idea de seguridad jurídica» «El principio de confianza legítima y el ordenamiento jurídico español», op. cit., p. 41. En la obra de J. GARCÍA LUENGO, El principio de protección de la confianza en Derecho Administrativo, puede encontrarse un completo análisis de su fundamentación, con particular referencia a la seguridad jurídica y a las objeciones que pueden formularse a esta concreta justificación del principio (op. cit., pp. 115-202).

${ }^{143}$ Vid. al respecto, y entre otras, las Sentencias del Tribunal Supremo de 1.VII.2000 (RJ 6855) y 26.VI.2001 (RJ 5739), en las que se resume la jurisprudencia comunitaria sobre los requisitos necesarios para la operatividad del principio.

También la doctrina se ha ocupado del análisis de los presupuestos que determinan la aplicación del principio de confianza legítima. En este sentido, y entre otros, puede verse la sistematización realizada por F. CASTILLO BLANCO, siguiendo a SCHWARZE, «El principio de confianza legítima y el ordenamiento jurídico español», op. cit., pp. 44-46, o por E. GUIСНО, La responsabilidad extracontractual de los poderes públicos según el Derecho comunitario, op. cit., pp. 355-358.

${ }^{144}$ Aunque son, ciertamente, mayoritarios los autores que defienden la aplicación del principio de protección de la confianza legítima en el ámbito normativo, como, por ejemplo, F. Castillo Blanco, (La protección de confianza en el Derecho Administrativo, op. cit., pp. 331-361), L. PARejo Alfonso, (Prólogo a la obra de F. CASTillo Blanco, La protección de confianza en el Derecho Administrativo, op. cit., p. 21), o F. SAINZ MORENO (Voz «Seguridad jurídica», Enciclopedia Jurídica Civitas, Vol. IV, op. cit., pp. 6108 y 9), existen algunas voces 
En nuestra Constitución la protección de estas expectativas no sólo encuentra fundamento, sin embargo, en la seguridad jurídica en su vertiente de protección de la confianza legítima; en el propio artículo 9.3 existe otro título que, sin duda, ampara la reparación de los daños efectivos y reales que un cambio normativo pueda producir en las posiciones jurídicas individuales: el principio de responsabilidad de todos los Poderes públicos y, por consencuencia, también del Poder Legislativo que establece dicho precepto y apartado ${ }^{145}$. No es posible examinar aquí el alcance de esa responsabilidad, ni los polémi$\cos$ y controvertidos términos en los que ha sido finalmente consagrada en el artículo 139.3 de la LRJ-PAC ${ }^{146}$, ni la confusa jurisprudencia recaida sobre ella en los últimos años ${ }^{147}$. Todos ellos constituyen aspectos de sobra analizados por la doctrina mas reciente, en particular por R. GALÁN VIOQUE en su obra sobre La responsabilidad del Estado Legislador ${ }^{148}$; a nuestro propósito es suficiente reseñar que, dándose los elementos determinantes de la responsabilidad, esto es, daño antijurídico, efectivo, evaluable económicamente e individualizado en relación a una persona o grupo de personas, los afectados tendrán derecho a indemnización ${ }^{149}$. Proceden, no obstante, por su

discrepantes como la de J. GARCía LUENGO, para quien «resulta muy difícil admitir como límite a las potestades del legislador una institución nacida como garantía frente a la actividad de la Administración Pública», aunque reconoce que nuestro Tribunal Constitucional la ha admitido expresamente. (El principio de protección de la confianza legítima en el Derecho Administrativo, op. cit., en su totalidad y, en particular, pp. 203-229).

${ }^{145} \mathrm{Ha}$ de advertirse, no obstante, de que no toda la doctrina comparte la idea de que el artículo 9.3 de la CE esté reconociendo la responsabilidad del Poder legislativo, aunque la posición mayoritaria se inclina, desde luego, porque así sea. Vid. sobre el tema, R. GALÁN VIOQUE, «La teoría de la responsabilidad del Estado legislador», $R A P$ núm. 115/2001, pp. 301 y 2.

${ }^{146}$ Las Administraciones Públicas indemnizarán a los particulares por la aplicación de actos legislativos de naturaleza no expropiatoria de derechos y que éstos no tengan el deber jurídico de soportar, cuando así se establezca en los propios actos legislativos y en los términos que especifiquen dichos actos».

${ }^{147}$ Me remito al respecto al resumen efectuado por R. GALÁN VIOQUE, en «La teoría de la responsabilidad del Estado legislador», op. cit., p. 310.

${ }^{148}$ Además de esta obra, pueden consultarse también los fundamentales estudios en la materia de J.A. SANTAMARÍA PASTOR, «La teoría del Estado Legislador», RAP núm. 68, 1972, J. Leguina Villa, La nueva Ley de Régimen jurídico de las Administraciones Públicas y del Procedimiento administrativo común (Dirs. J. Leguina Villa y M. SÁNCHEZ MoróN) Tecnos, Madrid, 1993 (pp. 394 y ss.), F. GARRIDO FALLA, «Sobre la responsabilidad del Estado Legislador», RAP, núm. 118, 1989 y «A vueltas con la responsabilidad del Estado Legislador» REDA núm. 81, 1994; F. Garrido Falla y J.M. Fernández Pastrana, Régimen jurídico y procedimiento de las Administraciones Públicas (Un estudio de la Ley 30/1992), $2^{\text {a }}$ Ed., Madrid, Civitas, 1995 (pp. 389 y ss.) y M.C. ALONSO GARCía, La responsabilidad patrimonial del Estado-Legislador, Marcial Pons, Madrid, 1999.

${ }^{149}$ Es evidente que es en la antijuridicidad en donde más escollos se presentan si, en la determinación de estos elementos, pretende importarse toda la dogmática desarrollada en la esfera de la responsabilidad de las Administraciones Públicas. R GALÁN, resumiendo la jurisprudencia existente en la materia, señala que el daño antijurídico es el que se traduce en un sacrificio especial entendiendo por tal el daño «especialmente grave e intenso porque los 
trascendencia algunas consideraciones sobre las conexiones existentes entre la responsabilidad sin ilegalidad y la confianza legítima; cuestión un tanto confusa aunque de singular interés. Es sabido que la jurisprudencia existente, hasta la fecha, diferencia entre la responsabilidad del legislador por daños derivados en aplicación de leyes inconstitucionales, en cuyo caso el Estado debe responder de todos los perjuicios causados ${ }^{150}$ y la que, por el contrario, tiene su origen en normas conformes con la Constitución. En estos últimos casos, que son los que nos interesan, el Estado ha de responder, con fundamento en un principio de justicia distributiva, por los daños de carácter anormal y singular. Se trata así de una responsabilidad excepcional. De una parte, porque su garantía no se extiende a cualquier perjuicio, abarca sólo una compensación «en equidad» que, con frecuencia, se relaciona, con el daño emergente y no con el lucro cesante; y, de otra, porque se exige que el perjuicio haya afectado de manera singular a un colectivo singularizado de personas y que revista el carácter de «anormal». Es justamente aquí donde entra en juego el principio de confianza legítima, que supone, de esta forma, un criterio, aunque no, desde luego, el único, para medir cuándo un daño puede reputarse anormal, criterio que, hasta ahora, se ha aplicado fundamentalmente en el ámbito del ejercicio de las actividades económicas. Ello significa, en síntesis, que puede haber responsabilidad aun cuando no se haya producido una vulneración del principio de confianza legítima por faltar unos de los presupuestos inherentes a éste, la creación previa por las autoridades públicas de una confianza en un comportamiento futuro ${ }^{151}$, lo que significa, en último término, que la responsabilidad del Poder legislativo puede cubrir supuestos no amparados por el principio de confianza legítima.

En conclusión, en nuestra Constitución, y a resultas del juego conjunto de los principios de responsabilidad patrimonial y seguridad jurídica, expresamente reconocidos por el Tribunal Supremo, «con entronque en el valor de la justicia, pilar del Estado de Derecho social y democrático» ${ }^{152}$, encuentra debido fundamento la indemnización de los perjuicios que un cambio normativo pueda causar, sin olvidar

perjuicios que se causan a unos destinatarios determinados excedan de los perjuicios normales que se derivan de la propia ley o porque se impongan unas cargas singulares que constituyan, por su despropocionalidad, una ruptura del principio de igualdad ante las cargas públicas» («La teoría de la responsabilidad del Estado legislador», op. cit., pp. 315).

${ }^{150} \mathrm{Me}$ remito al respecto al reciente estudio de M.C. ALONSO GARCíA, «La reciente jurisprudencia sobre la responsabilidad patrimonial del estado Legislador frente a daños derivados de Leyes inconstitucionales» (RAP núm.157/2002, pp. 215-240).

${ }^{151}$ Vid., al respecto y con fundamento en el Derecho comunitario las consideraciones efectuadas por GUICHOT REINA: La responsabilidad extracontractual de los poderes públicos según el Derecho comunitario, op. cit., pp. 355-358.

${ }^{152}$ Sentencia de 12.V.1997 (RJ 3976). 
tampoco el apoyo que, al respecto, puede aportar el principio de interdicción de la arbitrariedad de los Poderes públicos. Nótese bien en cualquier caso que estamos hablando de reparación de daños ciertos y reales causados por un cambio normativo; de ahí que cuando falte la tangibilidad del daño, no quepa esgrimir título alguno en defensa de una posible indemnización como el propio Tribunal Supremo ha destacado, entre otras, en su Sentencia de 20.X.1998 ${ }^{153}$.

Las mismas consideraciones y soluciones expuestas pueden servir como respuesta a aquellos otros supuestos en los que la expectativa, en la acepción más clásica de la figura, se conecta a un derecho in fie$r i$, a un derecho en formación. Fuera de las ocasiones en las que el ordenamiento jurídico dispensa expresamente protección a esos estados intermedios previos a la consolidación de un derecho, la regla general, de la que da buena cuenta la jurisprudencia, es, también, la de su plena disponibilidad por la norma sin que ante su desaparición o alteración sus titulares puedan alegar derecho alguno. En todos estos casos, nuestros Tribunales considerarán que los derechos futuros, simples o meras expectativas de presente, no pueden ser identificados, a menos que el ordenamiento establezca expresamente lo contrario, con posiciones jurídicas dignas de protección por el Derecho. Ahora bien, esta regla o principio cede, sin embargo, en los supuestos en los que el particular afectado demuestre que la pérdida o alteración de su expectativa le ha irrogado un perjuicio real y efectivo en su patrimonio, en cuyo caso, y en aplicación de los principios, ya expuestos, de seguridad jurídica, interdicción de la arbitrariedad y responsabilidad patrimonial de los Poderes públicos, tendrá derecho a la indemnización de los correspondientes perjucios ${ }^{154}$. Parece claro que la dificultad en estas hipótesis radica en localizar efectivamente esa lesión dentro del patrimonio de su titular lo que forzosamente conduce a lo que la doctrina administrativa ha denominado «una jurisprudencia del caso concreto» ${ }^{155}$.

${ }^{153}$ RJ 9455. En ella se condena al Gobierno canario al pago de las indemnizaciones por los perjuicios causados a las empresas distribuidoras de petróleo que no pudieron repercutir en las ventas de su carburante el Impuesto creado por una Ley del propio Parlamento canario a consecuencia de una Orden del Ministerio de Industria y Energía, coetánea en el tiempo, y que establecía los precios máximos de venta.

${ }^{154}$ Es el caso que contemplan diferentes Sentencias, de las que puede ser vir como exponente la de 16.V.2000 (RJ 5487), en las que se citan otras muchas anteriores en el mismo sentido.

Estas Sentencias confirman otras tantas dictadas por el Tribunal Suprerior de Justicia de las Islas Baleares, en las que se reconoce una indemnización a las empresas obligadas, como consecuencia de la entrada en vigor de Leyes de Ordenación y protección de áreas naturales de interés especial, a la paralización de obras de urbanización ya iniciadas.

${ }^{155}$ F. GARRIDO FALLA, entre otros, ha incidido de manera particular en esta idea. Me remito al respecto a las consideraciones efectuadas en F. GARRIDO FALLA y J.M. FERNÁNDEZ 
La solución a estas situaciones coincide, en definitiva, con la que, en esos mismos términos constitucionales, procede en los casos en los que las expectativas frustradas se concretan en una pretensión de estabilidad de determinado régimen jurídico. Ahora bien, siendo la solución la misma, ha de reconocerse que la jurisprudencia es mucho más permeable y sensible a la apreciación de daños y al reconocimiento del derecho a indemnización en estos últimos supuestos que en aquellos otros en los que lo que el particular alega es la lesión causada por la privación de un derecho futuro. La jurisprudencia, en definitiva, parece estimar que la existencia de perjuicios es más clara y cierta ante el cambio normativo que, en un plazo más o menos corto, obliga a los operadores económicos a adecuar su actuación a un nuevo régimen, que ante la privación de derechos que aún no se han consolidado. En cualquier caso, parece evidente que la cuestión sólo podrá resolverse atendiendo a las circunstancias del caso concreto, en una labor que, en muchos casos, resultará compleja y cuyo resultado estará abocado, sin duda, a la polémica, como señaladamente ocurrió con el caso del anticipo de la edad de jubilación, en el que el Tribunal Constitucional habló de la necesidad de paliar «los efectos negativos» que «origine una frustración de las expectativas existentes» que «pueden merecer algún género de compensación», sin mayores precisiones sobre su fundamento y alcance, lo que, finalmente, ha quedado como una afirmación de dudoso significado y carente, hasta la fecha, de desarrollo.

En general, puede decirse que las expectativas no generan, en principio, un derecho a su mantenimiento en beneficio de sus titulares que, por consiguiente, no pueden oponer título alguno en contrario ni esgrimir derecho compensatorio de ningún género; regla general que cede en los supuestos en los que, en atención a las circunstancias concretas del caso, se vulneren las bases del principio de seguridad jurídica entendida en términos de confianza legítima de los ciudadanos en la actuación de los poderes públicos o, aun, cuando, sin haberse vulnerado esa confianza, se produzcan daños incardinables en el ámbito de la responsabilidad de los Poderes públicos.

\section{BIBLIOGRAFÍA CITADA}

ACEDo, J.: «Retroactividad de las leyes», Revista Crítica de Derecho Inmobiliario, 1958.

Pastrana, La nueva Ley de Régimen jurídico de las Administraciones Públicas y del Procedimiento administrativo común. Civitas, Madrid, pp. 342 y 3, y F. GARRIDO FALLA, "A vueltas con la responsabilidad del Estado Legislador» (REDA núm. 81, 1994, p. 116). 
Albadalejo, M. (Dir.): Comentarios al Código civil y Compilaciones forales, T. I, Revista de Derecho privado, Madrid, 1978.

ALESSI, R.: Instituciones de Derecho Administrativo, T. II, traducción de la $3^{\text {a }}$ Edición italiana, Bosch, Barcelona, 1970, «La crisi attuale della nozione di Diritto soggettivo ed i suoi possibili riflesi nel campo del Diritto pubblico», Scritti Giuridici in memoria di V.E. Orlando, Padova-Cedam, 1957.

AlONSO GARCíA, M.C.: La responsabilidad patrimonial del Estado-Legislador, Marcial Pons, Madrid, 1999.

- «La reciente jurisprudencia sobre la responsabilidad patrimonial del Estado Legislador frente a daños derivados de Leyes inconstitucionales», RAP núm.157/2002.

AZURZA Y Oscoz, P.J.: «Sobre la naturaleza y disponibilidad de la posición de reservatario. Aportación a la teoría de la expectativa» RGLJ, Segunda época, T.XII, 1948.

Barbero, D.: Derecho privado, Ediciones Jurídicas Europa-America, Buenos Aires, 1967.

BobBio, N.: Contribución a la teoría del Derecho, Fernando TorresEditor, Valencia, 1980.

Bodenheimer, E.: Teoría del Derecho. Fondo de Cultura Económica, Mexico, 1940.

Bonnard, R.: Précis élémentaire de Droit Administratif, Sirey, Paris, 1996.

Boquera Oliver, J.M ${ }^{\mathrm{a}} .:$ «Criterio conceptual del Derecho Administrativo», $R A P$, núm. 42, 1963.

Capilla Roncero, F.: Voz «Derechos adquiridos». Enciclopedia jurídica Civitas, Vol. II, Madrid, 1995.

Carretero Pérez, A.: «Los derechos adquiridos y la edad de jubilación de jueces y magistrados», Actualidad Administrativa, núm 40, 1986.

CarriLlo Donaire J.A.: El Derecho de la seguridad y de la calidad industrial. Marcial Pons, Madrid, 2000.

CASTÁN, J.: Derecho civil español común y foral, T. I, Vol. I, Reus, Madrid, 1982.

Castillo Blanco, F.: La protección de confianza en el Derecho Administrativo, Marcial Pons, Madrid, 1998.

- «El principio europeo de confianza legítima y su incorporación al Ordenamiento Jurídico español», Noticias de la Unión Europea, núm. 205, 2002.

Clemente De Diego, F.: Instituciones de Derecho civil, T. I, Artes Gráficas Julio San Martín, 1959.

Coviello, N.: Doctrina general del Derecho civil, traducción al castellano de la $4^{a}$ edición italiana, Editorial Hispano-Américana, México, 1949.

De Castro, F.: Derecho civil de España, Civitas, Madrid, 1984. 
DíAz, E.: Sociología y Filosofía del Derecho, Taurus, 1984.

Díez-Picazo, L. y Gullón, A.: Sistema de Derecho civil, Tecnos, Madrid, 2000.

DíEz-PicAzo, L.: Experiencias jurídicas y teoría del Derecho, $3^{\mathrm{a}}$ Ed., Ariel, Barcelona, 1973.

Díez-Picazo, L. y MonTes, V.: Derecho privado y sistema económico, Departamento de Derecho civil, Universidad Autónoma de Madrid, 1979.

Duguit, L.: Traité de Droit Constitutionell, $3^{\circ}$ Ed. T. I, Ed. Boccard, Paris, 1927.

Escribano Collado, P.: Voz «Expectativa». Enciclopedia Jurídica, Civitas, 1995, Vol. II.

Espín CÁnovas, D.: Manual de Derecho civil español, Vol. I, Revista de Derecho Privado, Madrid, 1951.

FERRARI,V:: Acción jurídica y sistema normativo. Introducción a la Sociología del Derecho (Dykinson, Madrid, 2000).

FLEINER, F. Instituciones de Derecho Administrativo, Labor, Barcelona, 1933.

Forsthoff, E.: Tratado de Derecho Administrativo, Instituto de Estudios Políticos, Madrid, 1958.

— «Concepto y esencia del Estado social» en la recopilación de estudios de Forsthoff, Abendroth y Doehring, El Estado social, Centro de Estudios Constitucionales, Madrid, 1986.

FRANCHINI, F.: Le autorizzazioni amministrative constitutive di rapporti giuridici tra l'amministrazione i privati, Giuffrè, Milano, 1957.

Ripert, G. y Planiol, M.: Derecho civil, Editorial Pedagógica Iberoamericana, México, 1996.

Galán Vioque, R. La responsabilidad del Estado legislador, Cedecs, Barcelona, 2001.

— «La teoría de la responsabilidad del Estado legislador», $R A P$ núm. $115 / 2001$.

García de EnTerría, E.: Curso de Derecho Administrativo, I, $6^{\mathrm{a}}$ Ed., Madrid Civitas, 1993.

— «Sobre los derechos públicos subjetivos», REDA núm. 6, 1975.

GARCía LuENGO, L.: El principio de protección de la confianza legítima en el Derecho Administrativo, Civitas, Madrid, 2002.

GARCía MACHO, R.: «Contenido y límites del principio de confianza legítima: estudio sistemático en la jurisprudencia del Tribunal de Justicia», REDA, núm. 56, 1987.

GARCía MACHO, R.: Las relaciones de especial sujeción en la Constitución española, Tecnos, Madrid, 1992.

Garrido Falla, F. y Fernández Pastrana, J.M.: La nueva ley de Régimen jurídico de las Administraciones Públicas y del Procedimiento administrativo común. $2^{\mathrm{a}}$ ed., Madrid, Civitas, 1995. 
GARRIDO FALLA, F.: «A vueltas con la responsabilidad del Estado Legislador» (REDA núm. 81, 1994, pág. 116).

— «Las tres crisis del derecho subjetivo». Estudios dedicados al Profesor García Oviedo, Vol. I, Universidad de Sevilla, 1954.

- Tratado de Derecho Administrativo, Vol. I, Centro de Estudios Constitucionales, Madrid.

- Comentarios a la Constitución, Ed. Civitas, Madrid, 1980.

— «Sobre la responsabilidad del Estado Legislador», RAP, núm. 118, 1989.

Gaudemet, Y:. en el Prólogo a la obra de Yannakopoulos, C.: La notion de droits acquis en Droit Administratif français, LGDJ, Paris, 1997.

GAYA SICILIA, R.: El principio de irretroactividad de las Leyes en la Jurisprudencia constitucional, Montecorvo, Madrid, 1987.

GonZÁlez PÉREZ, J.: El principio general de la buena fe en el Derecho Administrativo, Civitas, Madrid, 1983.

GotTAnelli DE' Santi, G.: Voz «Diritti quesiti», Enciclopedia Jurídica.

GUICHOT ReINA, E.: La responsabilidad extracontractual de los poderes públicos según el Derecho comunitario, Tirant lo blanch, Valencia, 2001.

Hartley, T.C.: The Foundations of European Community Law, Ed. Clarendon Press, 1994.

HermitTe, M.A.: «Spéculateurs et technocrates. De la non-rétroactivité des lois à la confiance légitime», Revue Trimiestrelle de Droit Européen 1984.

Horgue Baena, C.: El deslinde de costas, Tecnos, Madrid, 1995.

HubEaU, F.: «Le principe de la protection de la confiance légitime dans la jurisprudence de la Cour de justice», Cahiers de Droit européen, 1983.

JELLINEK: Sistema dei diritti pubblici subbietivi, traducción italiana de la $3^{a}$ edición alemana, Società Editrice Libraria, Milán, 1912.

JÈzE, G.: Principios generales de Derecho I, Traducción de la $3^{\text {a }}$ Edición francesa publicada en 1925, Depalma, Buenos Aires, 1948.

Josserand, L.: Derecho civil I, Vol. I, Ediciones Jurídicas EuropaAmérica, Buenos Aires, 1951.

LAMOUREUX, F.: «The retroactivity of Community acts in the case law of the Court of justice», Common Market Law Review, 1983.

LaSAgabaster Herrarte, I.: Las relaciones de sujeción especial, Civitas, Madrid, 1994.

LAUbADÈRE, A.: Traité de droit administratif, $8^{\mathrm{a}}$ ed, 2 vols., LGDJ, Paris, 1980, Vol. I.

Lavilla Alsina, L.: Seguridad jurídica y función del Derecho, Real Academia de Legislación y Jurisprudencia, Madrid, 1999. 
Leguina Villa, J. «Principios generales del Derecho y Constitución» RAP núm. 114, 1987.

Leguina Villa, J.: (Dirs. Leguina Villa, J y Sánchez Morón, M.) La nueva Ley de Régimen jurídico de las Administraciones Públicas y del Procedimiento administrativo común, Tecnos, Madrid, 1993.

LETEMENDIA, M.: «Le principe de non rétroactivité en droit communautaire - Comparaison avec le droit anglais», Cahiers de Droit européen, 1977.

López BeníTEZ, M. Naturaleza y presupuestos constitucionales de las relaciones especiales de sujeción, Civitas, Madrid, 1994.

LóPEZ MENUdO, F.: El principio de irretroactividad en las normas jurídico-administrativas, Instituto García Oviedo. Universidad de Sevilla, 1982.

— «El principio de irretroactividad de las normas en la jurisprudencia constitucional». Estudios sobre la Constitución española. Homenaje al Profesor García de Enterría, T. I., Civitas, Madrid, 1991.

Lozano Serrano, C.: Exenciones tributarias y derechos adquiridos, Tecnos, Madrid, 1988.

Magariños Blanco, V.: La seguridad jurídica y el Estado de Derecho en España, Real Academia de Legislación y Jurisprudencia, Sevilla, 1993.

Manresa, J.M.: Comentarios al Código civil español, Comentarios al Código civil español T. I, 7ª Ed. Reus, Madrid, 1987.

Martín-Retortillo, S.: Derecho Administrativo económico I, La Ley, Madrid, 1988.

Mazeaud: Derecho civil, Parte I, Ediciones jurídicas Europa-América, Buenos Aires, 1976.

MerkL, A.: Teoría general del Derecho Administrativo. Editora Nacional, Méjico, 1980.

Nicolo, R.: «Voz» Aspettativa».

NiETO, A.: «Los derechos adquiridos de los funcionarios», RAP núm. 39, 1962.

- El mito de la Administración prusiana. Instituto García OviedoUniversidad de Sevilla, 1962.

- «Evolución expansiva del concepto de expropiación forzosa», RAP, núm. 38, 1962.

OrTEga Álvarez, L.: Voz «Derechos adquiridos de los funcionarios». Enciclopedia jurídica Civitas, 1995, vol. II.

Palma Fernández, J.L.: La seguridad jurídica ante la abundancia de normas, Centro de Estudios Políticos y Constitucionales, Madrid, 1997.

Parejo Alfonso, L.: Prólogo a la obra de Castillo Blanco, F.: La protección de confianza en el Derecho Administrativo Marcial Pons, Madrid, 1998. 
Peces-Barba, G.: «La Seguridad Jurídica desde la Filosofía del Derecho». Anuario de Derechos humanos. Facultad de Derecho de la Universidad Complutense, núm. 6, 1990.

Pelosi, A.C.: Voz «Aspettativa», Nuovo Digesto delle Discipline privatische, I, Utet, Tutin, 1987.

PÉreZ LuÑo, A.E.: La seguridad jurídica. Ariel, Barcelona, 1991.

RADBRUCH, G.: Introducción a la Filosofía del Derecho. $4^{\text {a }}$ edición en castellano de la alemana publicada en 1948 Fondo de Cultura Económica, Mexico, 1974.

Recasens Siches, L.: Panorama del pensamiento jurídico en el siglo XX, T. II, Porrúa, Méjico, 1963.

Roubier, P.: Le Droit Transitoire (Conflits des lois dans le temps), $2^{\mathrm{a}}$ ed. Dalloz et Sirey, Paris, 1960.

SAInz Moreno, F.: Voz «Seguridad jurídica», Enciclopedia Jurídica Civitas, 1995, Vol. IV.

SANTAMARÍA IBEAS, J.J.: Los valores superiores en la jurisprudencia del Tribunal Constitucional. Libertad, justicia, igualdad y pluralismo político, Ed. Dykinson, Madrid, 1997.

SANTAMaría PASTOR, J.A.: «La teoría del Estado Legislador», RAP núm. 68, 1972.

- Fundamentos de Derecho Administrativo I, Centro de Estudios Ramón Areces, Madrid, 1988.

SERrano Triana, A.: «La función de la seguridad jurídica en la doctrina del Tribunal Constitucional», Libro Homenaje al Profesor Jose Luis Villar Palasí, Ed. Civitas, Madrid, 1989.

SHARPSTON, E.: «Legitimate expectations and economic reality», European Law Review, 1990, págs. 103-160.

TAVERNIER, P.: «Le juge communautaire et l'application dans le temps des règlements C.E.E». Annuaire français de droit international, 1976.

Stober, R.: Derecho Administrativo económico, Ministerio para las Administraciones Públicas, Madrid, 1992, GROTTANELLI DE' SANTI, G.: Voz «Diritto Transitorio».

VALLEJO LOBETE, E.: «El respeto a la confianza legítima: importancia de este principio general del derecho en el Derecho comunitario» Gaceta Jurídica de la CE, B-27.

Villar Palasí, J.L.: Derecho Administrativo. Introducción y teoría de las normas. Universidad de Madrid, Madrid, 1968.

- La interpretación y los apotegmas jurídico-lógicos, Tecnos, Madrid, 1975.

WAELBROECK, D.: «Le principe de la non-retroactivité en droit communautaire à la lumière des arrêts isoglucose» Revue Trimiestrelle de Droit Européen, 1983.

WeIL, P.. Le Droit Administratif, 11 $1^{\text {a }}$ edición, PUF, Paris, 1964.

YANNAKOPOUlOS, C.: La notion de droits acquis en Droit Administratif français, LGDJ, Paris, 1997. 